\title{
Seismic Behavior of the San Pietro di Coppito Church Bell Tower in L'Aquila, Italy
}

\author{
Gabriele Milani $^{1, *}$, Salvatore Russo ${ }^{2}$, Marco Pizzolato $^{3}$ and Antonio Tralli ${ }^{3}$ \\ ${ }^{1}$ Dipartimento di Ingegneria Strutturale (DIS), Politecnico di Milano, Piazza Leonardo da Vinci 32, 20133 Milano, Italy \\ ${ }^{2}$ Università IUAV di Venezia, Venice, Dorsoduro 2206 ex-convento Terese 301223, Venice, Italy \\ ${ }^{3}$ Dipartimento di Ingegneria, Università di Ferrara, Via Saragat 1, 44100 Ferrara, Italy
}

\begin{abstract}
In the present paper, a non-linear numerical study on the $13^{\text {th }}$ century masonry bell tower of the church of San Pietro di Coppito is described. The aim is to have an insight into the causes at the base of the partial collapse suffered by the structure during the L'Aquila earthquake in 2009. To this aim, two different numerical analyses have been performed namely non-linear static (pushover) and limit analysis. In both cases, the same full 3D detailed FE model of the structure is adopted, changing the seismic load direction and assuming different distributions of the equivalent static horizontal load. When dealing with the FEM incremental analysis, a commercial code is utilized assuming for masonry a smeared crack isotropic model. For limit analysis, a non-commercial full 3D code developed by the authors is utilized. It provides limit good estimates of limit loads and failure mechanisms, to compare with standard FEM results. From numerical results, the role played by the actual geometry and by the masonry mechanical characteristics of the tower is envisaged, as well as a detailed comparison of failure mechanisms provided by the incremental FEM and limit analysis is provided. In all cases, the numerical analysis has given a valuable picture of damage mechanisms which can be compared with actual damage patterns so providing useful hints for the introduction of structural monitoring.
\end{abstract}

Keywords: Masonry tower, pushover, limit analysis, 3D finite elements.

\section{INTRODUCTION}

Historical masonry towers (bell towers, civic towers, tower-houses etc.) are present in the entire Italian peninsula, for instance bell towers are built next to almost every church. The great variety of uses is reflected by the heterogeneity of forms and constructive configurations. Their heights vary from the 60-70 meters of the highest $11^{\text {th }}-13^{\text {th }}$ century towers to 20-30 meters.

The evaluation of their structural safety is therefore an important issue in the maintenance of the historical heritage. Moreover, it is worth noting that a great interest has arisen after the sudden collapse of very famous towers, under sustained gravity loads such as the bell tower of San Marco in Venice or the Civic tower in Pavia. Seismic events, considering the large masses involved and the height on which they are distributed, generally represent even more dangerous actions to consider as well as the most important cause of damage and collapse of this kind of masonry structures.

A systematic analysis of the damages suffered by churches during earthquakes in Italy, has shown that the behavior of such structures can be better interpreted through their decomposition into architectural portions, defined as

*Address correspondence to this author at the Dipartimento di Ingegneria Strutturale (DIS), Politecnico di Milano, Piazza Leonardo da Vinci 32, 20133 Milano, Italy; Tel: +39 022399 4225; Fax: +39 022399 4220;

E-mail: milani@stru.polimi.it macro- elements, which are characterized by a structural response substantially independent of the global behavior of the church as a whole. According to the recent Italian GuideLines by the Minister for the Architectural and Cultural Heritage [1] bell tower structures are classified as typical isolated macro-elements and the failure loads associated to either global or partial belfry mechanisms have to be accounted for.

At present, a number of studies are available in the technical literature dealing with the structural analysis of masonry towers and a variety of analyses have been conducted, as for instance:

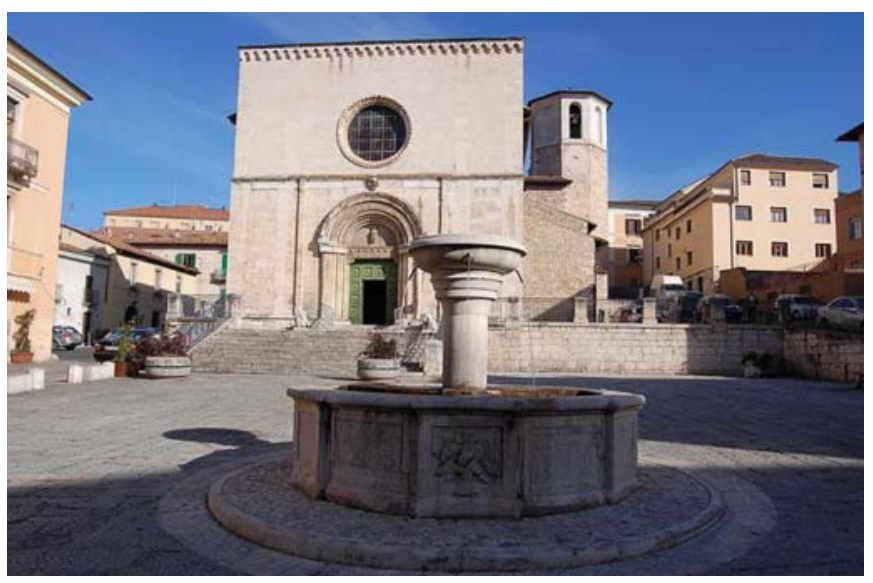

Fig. (1). Frontal view of the S.P. Coppito church. 
- utilization of nonlinear FE codes [2-5];

- Combined eigenvalues and experimental identification studies [6,7];

- 2D limit analyses assuming masonry as either a notension or a scarcely resistant in tension material $[8,9]$;

- 3D nonlinear dynamics of slender towers by specific fiber-element models [10];

- experimental and in situ tests [11].

In addition, the seismic assessment of a medieval masonry tower has been presented by two of the Authors [12] employing both 3D limit and nonlinear static analyses and full 2D dynamic simulations.

In this paper, the seismic behavior of the bell tower of the San Pietro di Coppito church in L'Aquila deeply injured by the 2009 earthquake is examined in detail.

In Section 2, the geometry of the tower, its mechanical characteristics and the actual damage occurred are briefly described. In Section 3 the results of modal analyses are presented. In Section 4 and Section 5 a series of different incremental nonlinear FE analyses performed using DIANA 9.4.3 commercial code is presented and compared with full 3D limit analyses performed using a non-commercial code developed by one of the Authors [12-16] Both global and local mechanisms are investigated.

From numerical results, the role played by the actual geometry of the tower is envisaged, as well as a detailed comparison of failure mechanisms provided by the incremental FE procedure and limit analysis is provided. In all cases, the numerical analysis together with in situ tests provides a valuable picture of possible damage mechanisms. The numerical damage pattern so evaluated can finally be compared with the existing one.

\section{DESCRIPTION OF THE TOWER AND MECHANI- CAL PROPERTIES}

The church of San Pietro di Coppito in L'Aquila, (see Fig. 1) damaged by the earthquake of 6th April 2009, dates back to the mid-thirteenth century; it was progressively transformed up to the nineteenth century and then restored to its initial appearance in 1969-1972.

The structural system of the church, Fig. (2), is constituted by a single nave with a single lateral corridor, which is at the base of a strong structural asymmetry. Furthermore, the transept is divided into two parts with different longitudinal plan-altimetric configuration.

On the right side of the church -very complex both for the symmetry and structure- there is a bell tower, built near the apse and transept. It exhibits an octagonal hollow cross section and inside there is an unusual spiral staircase that goes up to the belfry. The bell tower is 25 meters high; the radius of the circle which circumscribes the outer perimeter is about $8.14 \mathrm{~m}$ ) so the slenderness of the tower is about 3 . The walls of the stem are made up of two interconnected layers built by rough-hewn blocks. The thickness is around $1.75 \mathrm{~m}$ (Fig 2) until the height of $12 \mathrm{~m}$, while the thickness reduces, up to the belfry, to $1.4 \mathrm{~m}$ (Fig 2). The thickness of the external leaf made with bigger and more regular stones is approximately of $40 \mathrm{~cm}$. Between the stem and the belfry a concrete curb $30 \mathrm{~cm}$ thick and built in recent years is present. The belfry is built using less thick masonry walls $(1.15 \mathrm{~m})$ with niches and equi-spaced windows. After the earthquake occurred in April 2009, in direction NW-SE (Fig 2), the belfry collapsed on the side of the church, devastating completely the roof of the transept. Also the stem of the tower has suffered the seismic event, showing evident shear cracks. The size of the crack is serious, but did not cause the collapse of the structure. Some documents show that during the
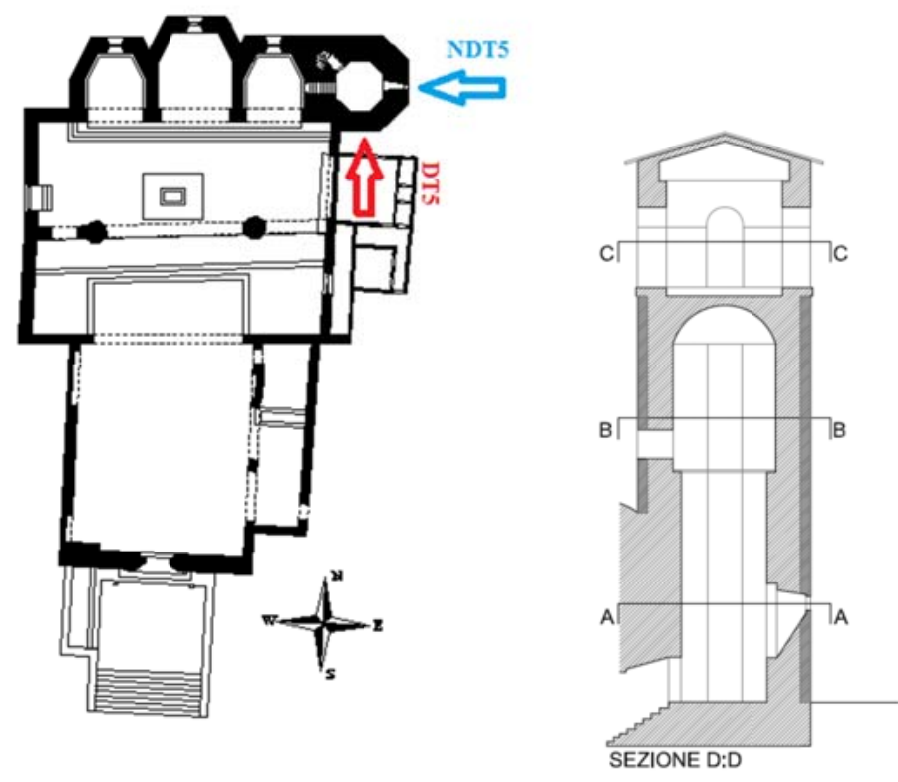

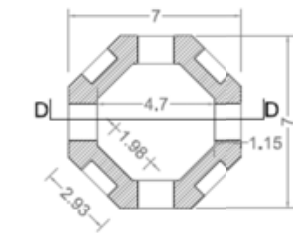

SEZIONE C:C

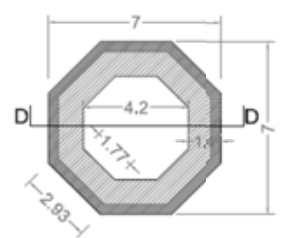

SEZIONE B:B

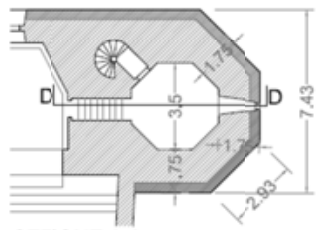

SEZIONE A:A

Fig. (2). Plane view of the church and bell tower sections 
last restoration intervention, the belfry was reinforced and stiffened and the concrete curb may be considered as part of such intervention. As a matter of fact, in the ruins of the collapsed belfry the presence of the curb was clearly found. Therefore, the assumption made is that the stiffened belfry, during the earthquake, has lost the flatness of the support on the stem (it has broken into the top right side of the apse).

The walls made by rough-hewn blocks have generally very irregular external surfaces and there is almost lack of connection between external walls and inner nucleus, as demonstrated by the photographic documentation reported in Fig. (3a). As a matter of fact, the collapse of the upper part of the structure put in evidence the actual distribution of blocks along the thickness of the wall and the interconnection between external and internal leafs.

An extensive campaign of in situ tests has been performed. In Table 1 and Table $\mathbf{2}$ the results obtained for the external leaf are shown; for the internal leaf, built up by smaller stones masonry, and for the remaining parts of the tower no experimental data are at present available.

The bell tower is connected to the contiguous church, having in common an irregular contact surface (Fig. 3b). In particular, the common edge is constituted by a rectangular flat portion of the tower facing the transept up to a height of about $13.5 \mathrm{~m}$ and by two faces looking towards the apse, up to a height of about $11 \mathrm{~m}$. To properly take into account such interconnection, suitable displacement constraints along $\mathrm{X}$ and $\mathrm{Y}$ direction in the FE model, Fig. (4), are inserted.

From existing documentation, it is known that a wooden roof was present, but neither geometric surveys nor existing drawings that allow identifying the exact morphology are at disposal. Hence, in what follows, a distributed vertical load equal to $16 \mathrm{kN} / \mathrm{m}^{2}$ is applied to the numerical model. Conversely, it is known that there were two bells, one with a diameter of about $80 \mathrm{~cm}$ and the other with a diameter of 30 $\mathrm{cm}$. The weight of the bells is determined using literature data for bells having the same diameter. In particular, it is assumed a weight equal to $4 \mathrm{kN}$ and $1.30 \mathrm{kN}$ for the bell with a diameter equal to $80 \mathrm{~cm}$ and $30 \mathrm{~cm}$ respectively. An additional load equal to $1 \mathrm{kN}$ is assumed for the knocker. Finally, it is supposed that bells were supported by a suitable steel frame. Vertical pressure representing the roof weigh is applied in correspondence of the head of the walls of the belfry, while bells weight is applied to the model by means of vertical pressures on elements belonging to the extrados of the dome infill, as shown in Fig. (4).

Unfortunately, exhaustive mechanical characterization tests are not available and the geometric survey at disposal is not accurate. For this reason, the lower level of knowledge available in the Italian code for existing structures (LC1) is assumed.

As a consequence of this choice, while the mechanical properties of external leafs at the base of the tower can be derived by Table $\mathbf{1}$, the mechanical properties of the internal

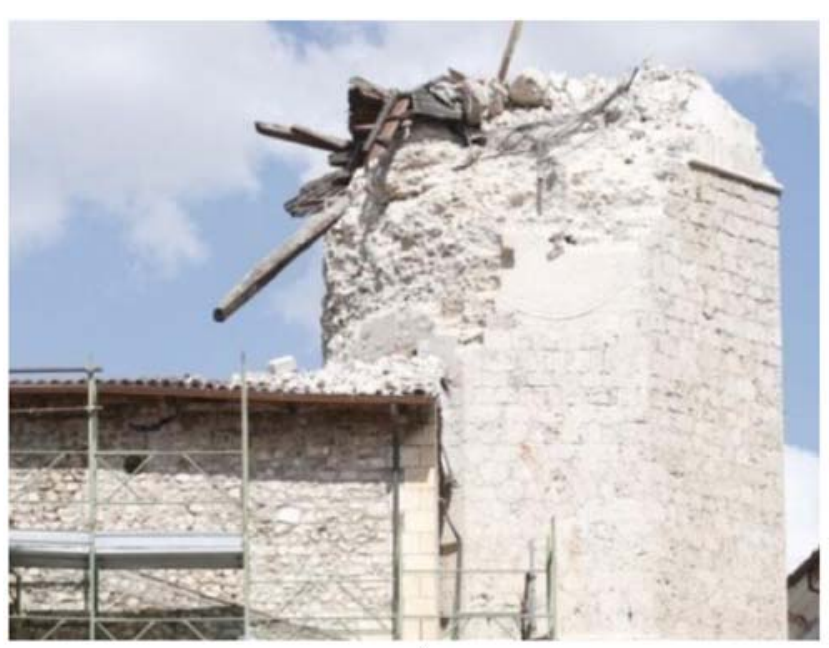

a)

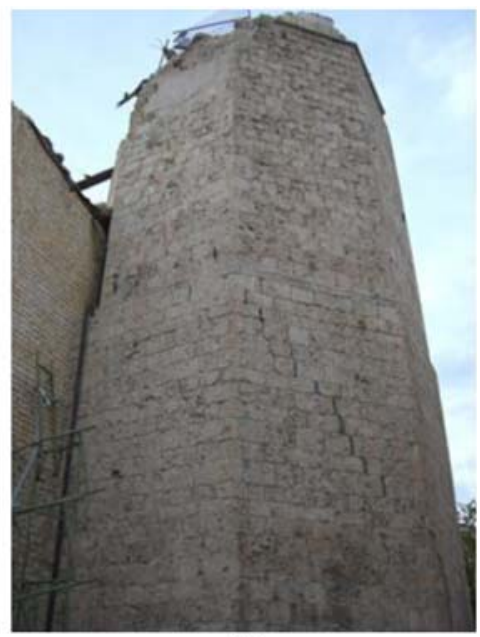

b)

Fig. (3). Photographic documentation of the collapse of the bell tower: a) detail of the interconnection between external walls and inner nucleus b) detail of the interconnection between the tower and the church.

Table 1. Mechanical Properties of the Masonry Obtained by Destructive Tests

\begin{tabular}{|c|c|c|c|c|c|}
\hline Location & Identification code & $E_{c}\left(N / m^{2}\right)$ & $\sigma_{c}\left(N / m^{2}\right)$ & $\mathbf{f}_{\mathrm{ct},}\left(\mathrm{N} / \mathbf{m m}^{2}\right)$ & Density $\left(\mathrm{kg} / \mathrm{m}^{3}\right)$ \\
\hline
\end{tabular}

Table 2. Mechanical Properties of the Masonry Obtained by Sonic Tests

\begin{tabular}{|c|c|c|c|c|c|}
\hline Location & Identification code & Mean values, velocity $(\mathbf{m} / \mathbf{s e c})$ & SD $(\mathbf{m} / \mathbf{s e c})$ & $\mathbf{C V}$ & $\mathbf{E}_{\mathbf{d}}\left(\mathbf{N} / \mathbf{m m}^{2}\right)$ \\
\hline \hline Bell tower- external leaf & NDT5 & 1263 & 459 & 0.36 & 702.16 \\
\hline
\end{tabular}


leaf and in the other parts of the structure are taken from table C8A.2.1 reported in the Italian norms [17] and for each material the lower bounds values of strength and the average values for elastic moduli as prescribed by the Norms are assumed respectively. The mechanical properties of the infill have been deduced from those assumed for other bell towers [12].

Each value of material properties is then divided further by the confidence factor related to the level of knowledge FC, in this case equal to1.35. Mechanical properties used for the analysis are listed in Table $\mathbf{3}$.

\section{MODAL ANALYSIS}

In order to assess a global seismic response of the bell tower under study, a modal analysis was performed on an accurate 3-D FEM model, even though the ability of such a model to represent the actual behavior of the construction is limited, due to the tendency of masonry structures to alter significantly their behavior in response to dynamic seismic action. Moreover the knowledge of eigen-values, eigenmodes and the corresponding activated mass is required for the determination of the shape of the horizontal load distribution to utilize within the pushover procedure.

The structure is regular in plane but irregular in elevation, due to the sudden changes of thickness of the walls (and hence of mass) and the presence of the constraints along the height, representing the common edge with the contiguous church.

The structural factor $q$ is calculated as prescribed by the Guide Lines provided by the Italian Ministry for the Cultural Heritage [1], taking into account the irregularity in elevation and results equal to 2.8 . The spectrum adopted for the modal analysis is related to a return period of 475 years and a soil type B; the parameters which characterize the spectrum are defined according the Italian Norms (NTC 2008). For modal analyses, only elastic properties are needed: they are summarized in Table 3 .
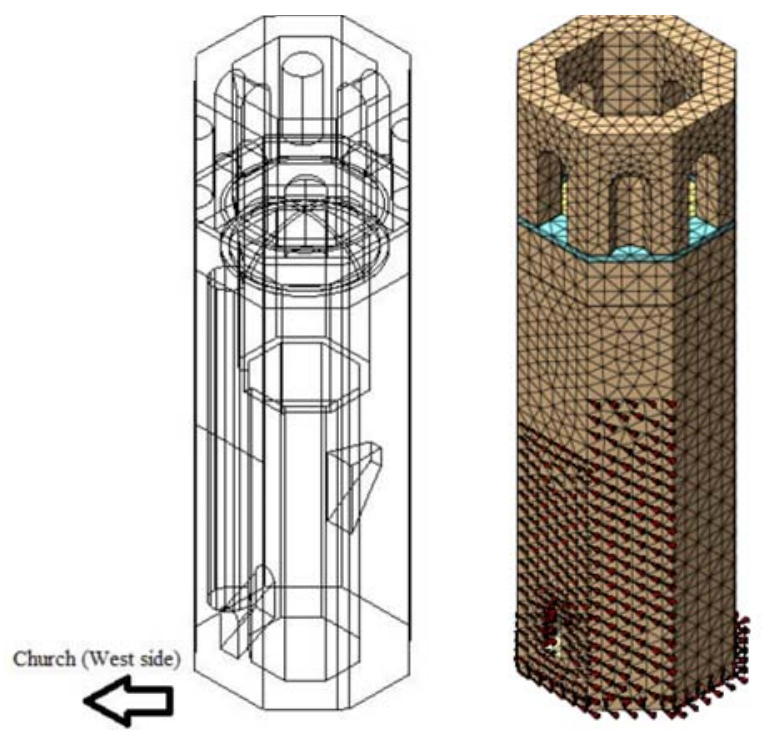

Periods and excited mass in $\mathrm{X}$ and $\mathrm{Y}$ direction from modal analysis, together with the activated mass percentage are listed respectively in Table $\mathbf{4}$ and Table 5. Only modes with excited mass greater than $5 \%$ are reported, moreover the corresponding modal deformed shapes are depicted in Fig. (5) and Fig (6). It is worth noting that the largest excited mass in $\mathrm{X}$ direction corresponds to the first mode and represents the $33.25 \%$ of the total mass, whereas in Y direction corresponds to the second mode and it is equal to $30.65 \%$. The low values of excited mass corresponding to the first mode in $\mathrm{Y}$ direction are due to the presence of the constraints simulating the connection to the church, that does not allow the movement of the lower part of the tower where a large part of the mass is concentrated.

The resulting response conveniently represents the behavior of the structure during the earthquake, in particular mode 8 deformed shape along Y direction (Fig. 6), may be regarded as representing conventionally the collapse mechanism of the belfry.

\section{INCREMENTAL NON-LINEAR AND LIMIT ANALYSIS}

In the last few years, non-linear static procedures have been proposed by many national codes for a safety evaluation of masonry structures which account properly for the non-linearity exhibited by the masonry material even at low levels of the external loads. These methods, generally known as "pushover" approaches, have recently assumed a large relevance, especially for the assessment of existing buildings, also in light of code of practice requirements. Basically, a computational model of the structure is built with a proper distribution of horizontal static loads, which are gradually increased with the aim of "pushing" the structure into the nonlinear field. Here full 3D pushover analyses are conducted on the tower under consideration, investigating the role played by the boundary condition and the presence of the concrete curb. In addition, 3D upper bound non-linear analyses are conducted by means of the approach firstly proposed in [18] and further developed in [19-21] in order to

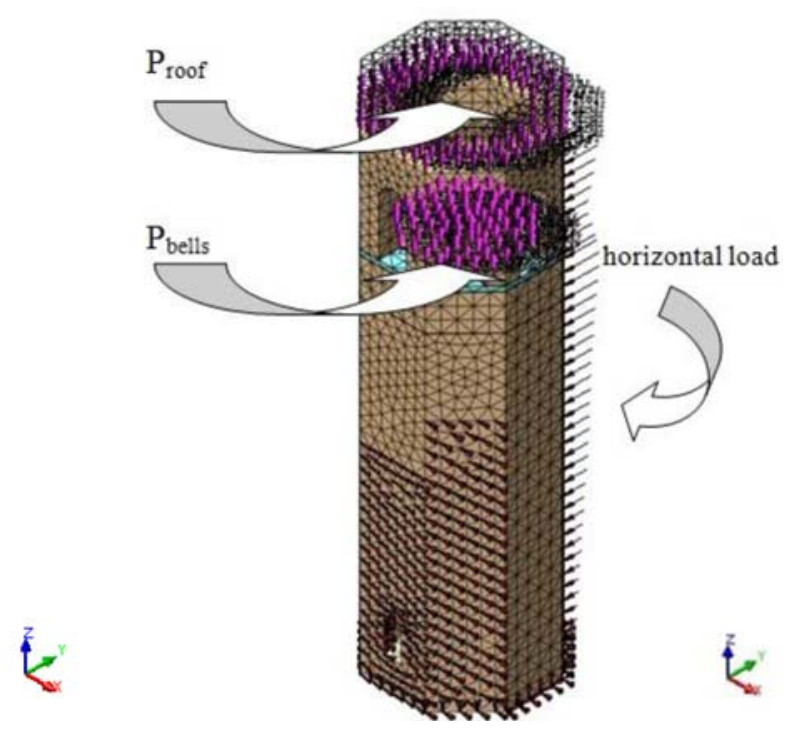

Fig. (4). Left: Axonometric view of the tower. Center: FE discretization. Right: schematization of extra-loads (except self-weight) applied to the model. 
compare failure loads and failure mechanics provided by the non-linear method.

The pushover analysis has been performed using DIANA 9.4.3 [22] (see also[23] for a structural application performed with the same software), a commercial code allowing full non-linear analyses by means of the so called "multi directional fixed crack model".

For both non-linear and limit analyses, 23594 four noded tetrahedron elements and 5909 nodes are used. The mechanical properties adopted for the pushover analyses are reported in Table 3. When dealing with limit analyses, approximately the same peak values of tensile and compressive strength utilized for pushover are adopted as limit strengths, as indicated in Table 6. More in detail, within limit analyses computations, tetrahedron elements are supposed infinitely resistant and plastic dissipation is allowed exclusively on inter- faces between adjoining elements, supposed behaving as an isotropic material with Mohr Coulomb failure criterion with tension cutoff and linearized elliptic cap in compression. To summarize, for the limit analysis model, five inelastic parameters are required to fully characterize interfaces at failure, namely masonry cohesion $C$, friction angle $\Phi$, tensile strength $f_{t}$, compression strength $f_{c}$ and shape of the linearized elliptic compression cap $\Phi_{2}$.

Within both approaches, two horizontal loads distributions along the height are comparatively analyzed, as illustrated in Fig. (7). For the sake of simplicity, loads are assumed applied on the external edges both in the $\mathrm{X}$ and $\mathrm{Y}$ directions. While authors are aware that a rigorous approach would require the application of a distributed horizontal load element by element, this could result very tedious within a commercial environment and it is therefore avoided. Con-

Table 3. Mechanical Properties of the Materials

\begin{tabular}{|c|c|c|c|c|c|c|}
\hline \multicolumn{7}{|c|}{ MAIN FRAME OF THE BELL TOWER } \\
\hline $\mathrm{f}_{\mathrm{c}}\left[\mathrm{KN} / \mathrm{m}^{2}\right]$ & $\tau_{0}\left[\mathrm{KN} / \mathrm{m}^{2}\right]$ & $\mathrm{E}\left[\mathrm{KN} / \mathrm{m}^{2}\right]$ & $\mathrm{G}\left[\mathrm{KN} / \mathrm{m}^{2}\right]$ & $\mathrm{w}\left[\mathrm{KN} / \mathrm{m}^{3}\right]$ & $\mathrm{ft}\left[\mathrm{KN} / \mathrm{m}^{2}\right]$ & $\varepsilon_{\mathrm{u}, \mathrm{t}}$ \\
\hline 1481 & 26 & 911111 & 303704 & 20 & 100 & 0.0003 \\
\hline \multicolumn{7}{|c|}{ VAULTS AND BELFRY } \\
\hline $\mathrm{f}_{\mathrm{c}}\left[\mathrm{KN} / \mathrm{m}^{2}\right]$ & $\tau_{0}\left[\mathrm{KN} / \mathrm{m}^{2}\right]$ & $\mathrm{E}\left[\mathrm{KN} / \mathrm{m}^{2}\right]$ & $\mathrm{G}\left[\mathrm{KN} / \mathrm{m}^{2}\right]$ & $\mathrm{w}\left[\mathrm{KN} / \mathrm{m}^{3}\right]$ & $\mathrm{ft}\left[\mathrm{KN} / \mathrm{m}^{2}\right]$ & $\varepsilon_{\mathrm{u}, \mathrm{t}}$ \\
\hline 1778 & 44 & 1111111 & 370370 & 18 & 178 & 0.0003 \\
\hline \multicolumn{7}{|c|}{ INFILL } \\
\hline $\mathrm{f}_{\mathrm{c}}\left[\mathrm{KN} / \mathrm{m}^{2}\right]$ & $\tau_{0}\left[\mathrm{KN} / \mathrm{m}^{2}\right]$ & $\mathrm{E}\left[\mathrm{KN} / \mathrm{m}^{2}\right]$ & $\mathrm{G}\left[\mathrm{KN} / \mathrm{m}^{2}\right]$ & $\mathrm{w}\left[\mathrm{KN} / \mathrm{m}^{3}\right]$ & $\mathrm{ft}\left[\mathrm{KN} / \mathrm{m}^{2}\right]$ & $\varepsilon_{\mathrm{u}, \mathrm{t}}$ \\
\hline 741 & 37 & 688889 & 296296 & 16 & 100 & 0.0003 \\
\hline \multicolumn{7}{|c|}{ KERBS } \\
\hline \multicolumn{2}{|c|}{$\mathrm{E}\left[\mathrm{KN} / \mathrm{m}^{2}\right]$} & \multicolumn{2}{|c|}{$\mathrm{G}\left[\mathrm{KN} / \mathrm{m}^{2}\right]$} & \multicolumn{3}{|c|}{$\mathrm{w}\left[\mathrm{KN} / \mathrm{m}^{3}\right]$} \\
\hline \multicolumn{2}{|c|}{31476000} & \multicolumn{2}{|r|}{12590400} & \multicolumn{3}{|c|}{25} \\
\hline
\end{tabular}

Table 4. Modes in X Direction

\begin{tabular}{|c|c|c|c|}
\hline \multicolumn{2}{|c|}{ X Direction } \\
\hline \hline Mode & Frequency [Hz] & Period [s] & Partecipation Mass \% \\
\hline 1 & 2.057 & 0.486 & 6.99 \\
\hline 2 & 2.160 & 0.463 & 19.18 \\
\hline 9 & 8.350 & 0.119 & 6.29 \\
\hline
\end{tabular}

Table 5. Modes in Y Direction

\begin{tabular}{|c|c|c|c|}
\hline \multicolumn{4}{|c|}{ Y Direction } \\
\hline Mode & Frequency [Hz] & Period [s] & Partecipation Mass \% \\
\hline 1 & 2.057 & 0.486 & 6.94 \\
\hline 2 & 2.160 & 0.463 & 30.65 \\
\hline 8 & 9.314 & 0.107 & 12.07 \\
\hline
\end{tabular}




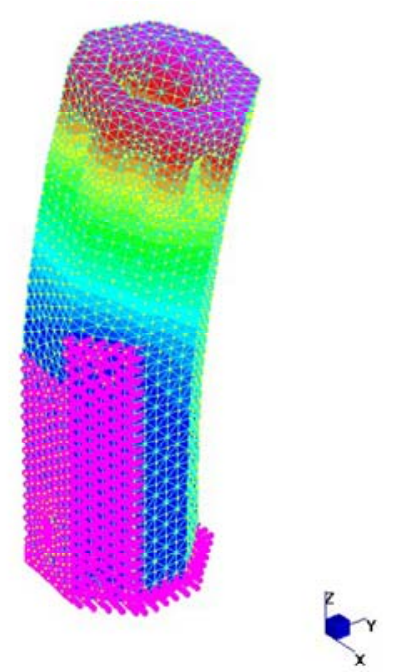

Mode 1: Period $0.486 \mathrm{~s}$, excited mass: $33.25 \%$
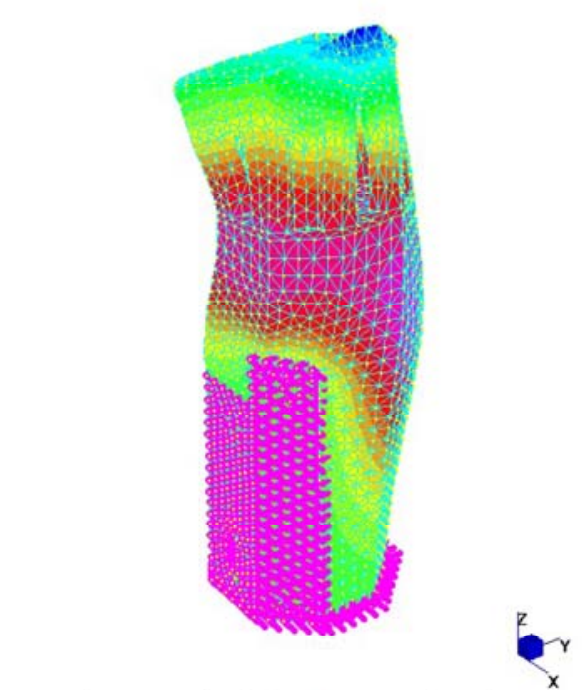

Mode 7: Period $0.119 \mathrm{~s}$, excited mass $19.18 \%$

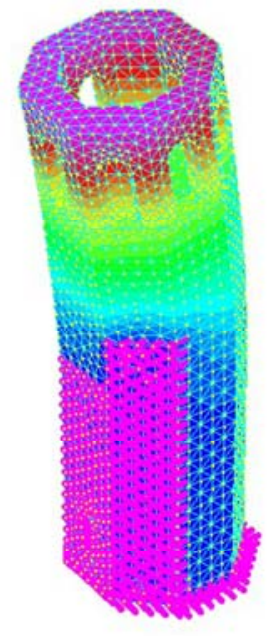

Mode 2: Period $0.463 \mathrm{~s}$, excited mass $6.99 \%$
Fig. (5). Modes in X direction.

versely, the exact application of the load element by element is very straightforward when dealing with the limit analysis approach, being such code non-commercial and developed by one of the authors. It is therefore possible to estimate the level of approximation introduced when such kind of choice is adopted, at least strictly for limit analysis but, by extension, for the pushover approach too. In the former case, it has been experienced very little difference between limit loads provided by models with horizontal forces applied element by element or on the edges (less than $3 \%$ on ultimate base shear in the most unfavorable case), meaning that the latter approximation is suitable from an engineering point of view.

Italian Norms [24] when dealing with the non-linear static analysis prescribe the evaluation of the load carrying capacity by means of two configurations of horizontal forces: the first provides a distribution of forces derived by the assumption of a linear variation of acceleration along the height (G1) while for the second it is assumed a constant ac- celeration (G2). As prescribed by the Instructions for NTC 2008 [17] the first distribution of forces of Group 1 and Group 2 can be applied independently of the participating mass activated by the first mode. The distribution of masses along the height is depicted in Fig. (8-a) whereas in Fig. (8-b) the corresponding distributions of forces in the hypothesis of linear (G1, curve a) and constant (G2, curve b) acceleration are represented. In Fig. (9) and Fig. (10) pushover curves obtained for $\mathrm{X}$ and $\mathrm{Y}$ direction (both positive and negative verse) under both load distributions hypotheses and limit analysis collapse loads are represented. Good agreement is found between the two alternative models regarding failure loads, the comparison giving a good confidence on the numerical collapse loads so evaluated.

From simulations results, it is interesting to notice that the curve with lower peak, for $\mathrm{X}$ direction, is that relative to the distribution of forces G1 and negative direction, while for $\mathrm{Y}$ direction the curve with lower load peak is again that 


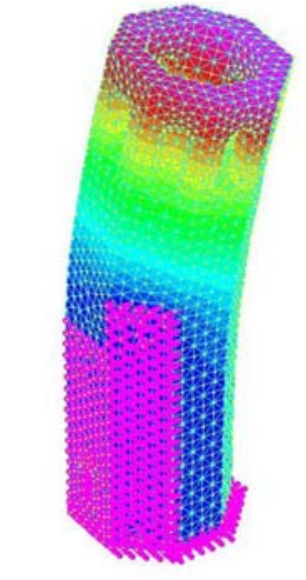

Mode 1: Period $0.486 \mathrm{~s}$, excited mass $6.94 \%$

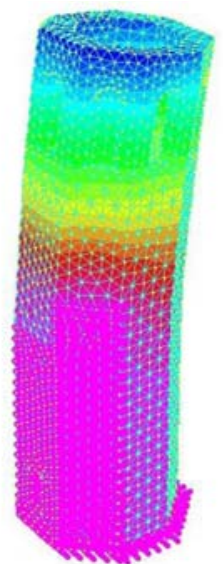

Mode 2: Period $0.463 \mathrm{~s}$, excited mass $30.65 \%$

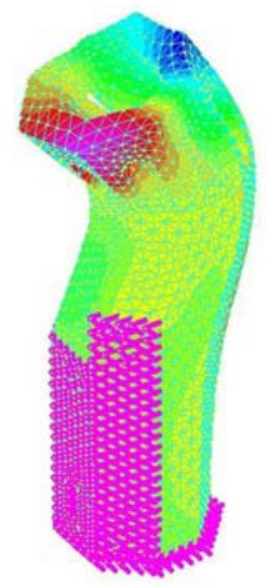

Mode 8: Period $0.107 \mathrm{~s}$, excited mass $12.07 \%$

Fig. (6). Modes in Y direction.
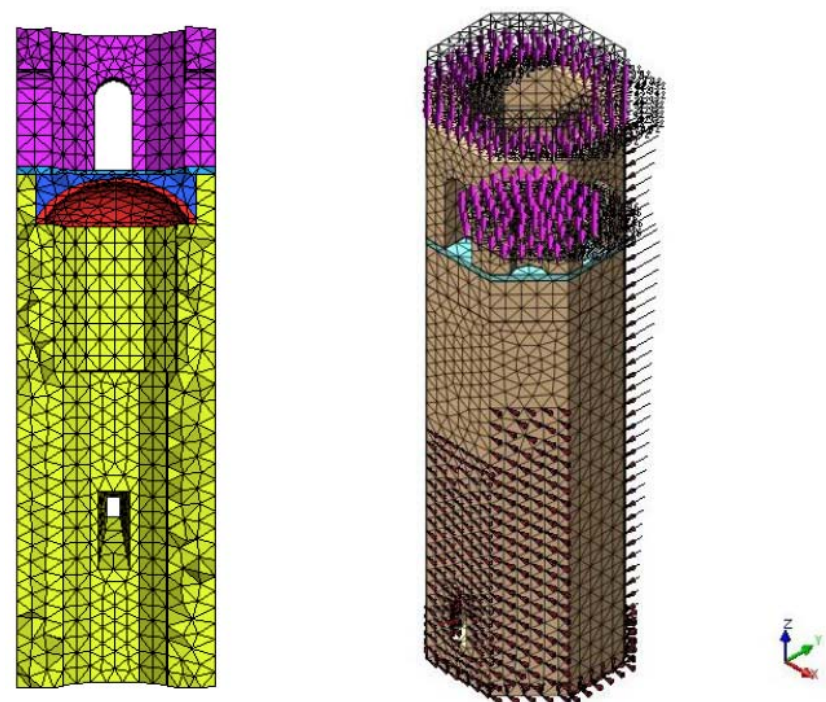

Fig. (7). FE models used for limit and incremental non linear analysis (23594 elements and 5909 nodes).

Table 6. Mechanical Properties Assumed for the Interfaces in the Limit Analysis Model

\begin{tabular}{|c|c|c|c|c|}
\hline $\mathrm{f}_{\mathrm{t}}$ & $\mathrm{c}$ & $\Phi$ & $\mathrm{f}_{\mathrm{c}}$ & $\Phi_{2}$ \\
\hline Tensile Strength [MPa] & Cohesion [MPa] & $\begin{array}{c}\text { Friction Angle } \\
{\left[{ }^{\circ}\right]}\end{array}$ & $\begin{array}{c}\text { Compressive Strength } \\
{[\mathrm{MPa}]}\end{array}$ & $\begin{array}{l}\text { Shape of the Linearized Compressive Cap } \\
\left.\qquad{ }^{\circ}\right]\end{array}$ \\
\hline \multicolumn{5}{|c|}{ MAIN FRAME OF THE BELL TOWER } \\
\hline 0.1 & 0.1 & 30 & 1.5 & 45 \\
\hline 0.18 & 0.15 & 30 & 1.8 & 60 \\
\hline \multicolumn{5}{|c|}{ INFILL } \\
\hline 0.05 & 0.05 & 45 & 0.8 & 90 \\
\hline
\end{tabular}

relative to the distribution of forces G1 but positive direction.

An apparently debatable result is found when dealing with $\mathrm{X}+$ and $\mathrm{Y}$ - direction with $\mathrm{G} 2$ distribution. As a matter of fact, G1 and G2 distributions give quite different collapse loads, intended as total base shear at peak, being the situation corresponding to $\mathrm{G} 2$ the most resistant. These apparently dubious results may be explained having a look into deformed 

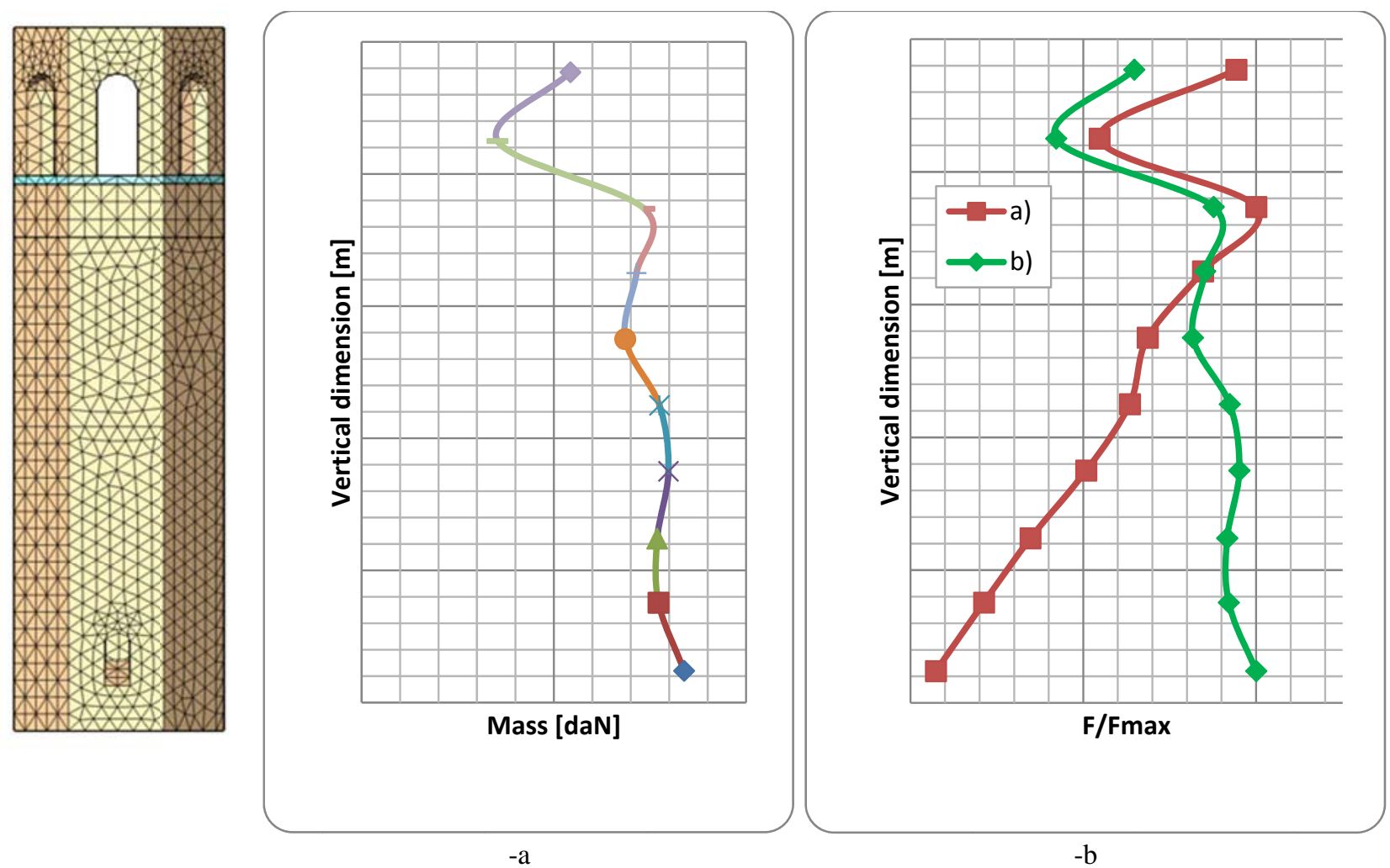

Fig. (8). -a: Distribution of masses along the height.-b: Distribution of forces a) curve corresponds to G1 case and b) curve to G2 case.

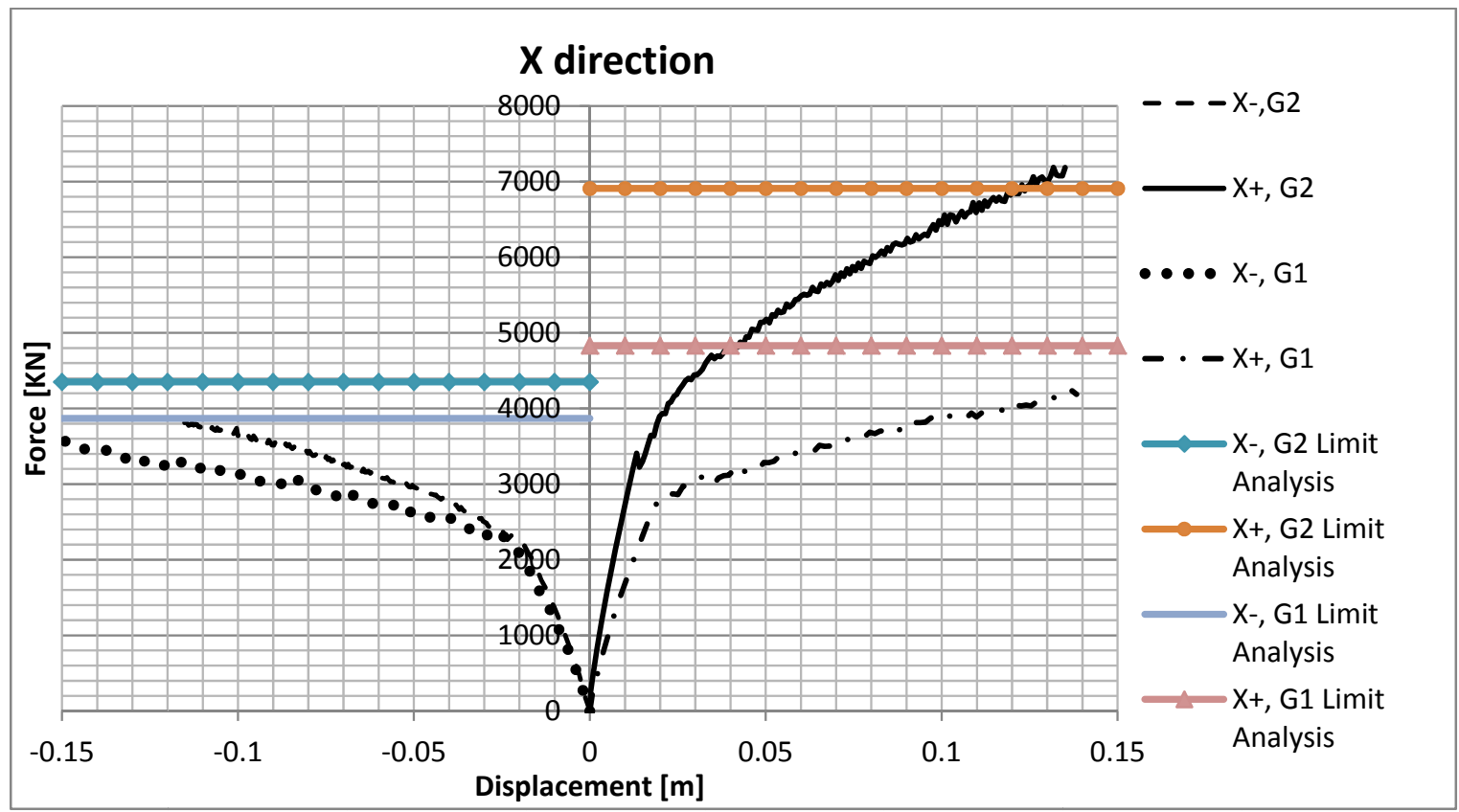

Fig. (9). Force-Displacement curve for X- direction.

shapes provided by both limit analysis and incremental nonlinear code, reported in Fig. (11), Fig. (12) (incremental code) and Fig. (13) (limit analysis) especially for what concerns the failure mechanism.
It clearly involves the lower part of the structure, with the formation of a well-defined inclined cracked surface departing from the upper portion of the constrained vertical edge and proceeding deeply from the top to the bottom, up to the base, thus activating much more mass with respect to both G1 case and the contrary direction (X- and $\mathrm{Y}+$ respectively). 


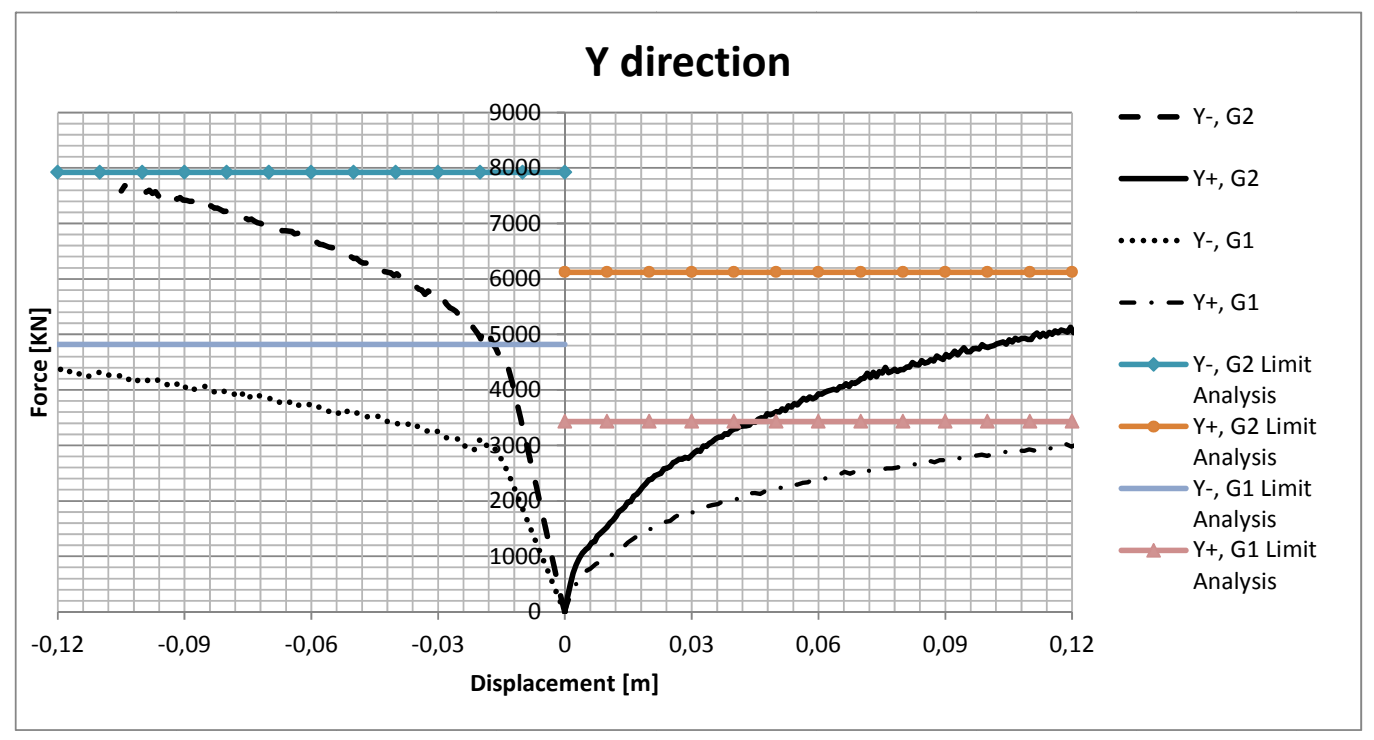

Fig. (10). Force-Displacement curve for Y- direction.

X- direction G1 distribution
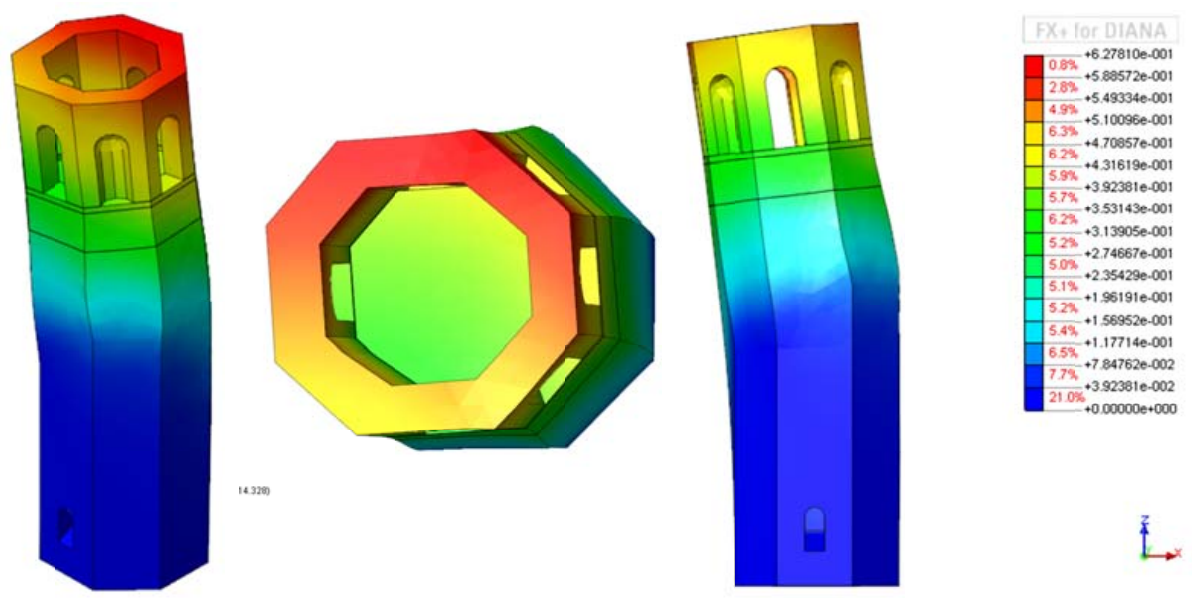

$\mathrm{X}+$ direction $\mathrm{G} 1$ distribution
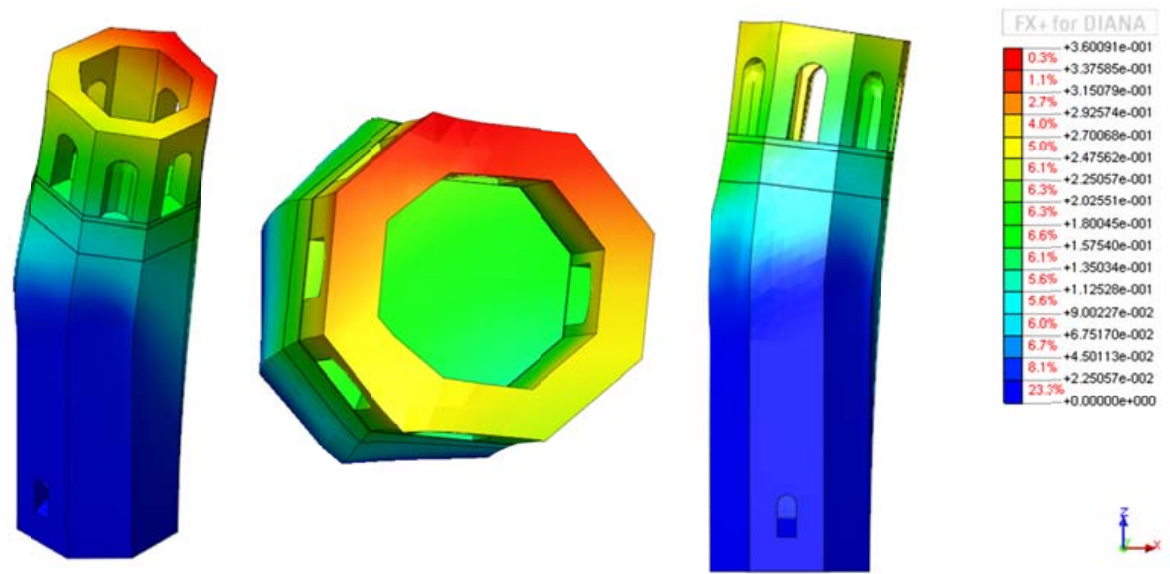

Fig. (11). Deformed shapes at peak provided by the commercial code. X direction.

In figures from Fig. (14-17) crack patterns provided by DIANA program and referred alternatively to $\mathrm{X}$ and $\mathrm{Y}$ direction and G1 or G2 load distributions respectively are repre- sented. As already pointed out, crack patterns provide a good insight into the actual failure mechanism active in the considered load case. The failure mechanisms is rather well de- 


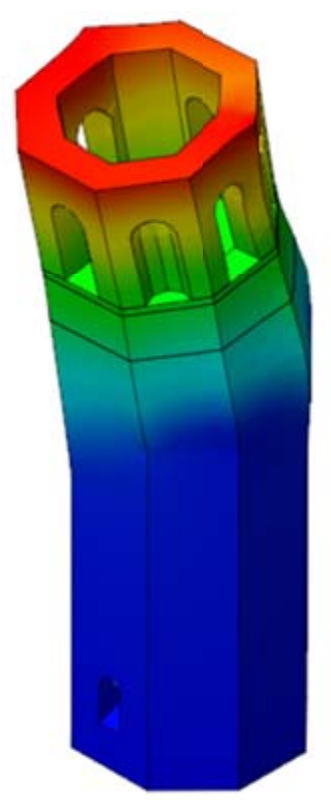

Y- direction G1 distribution
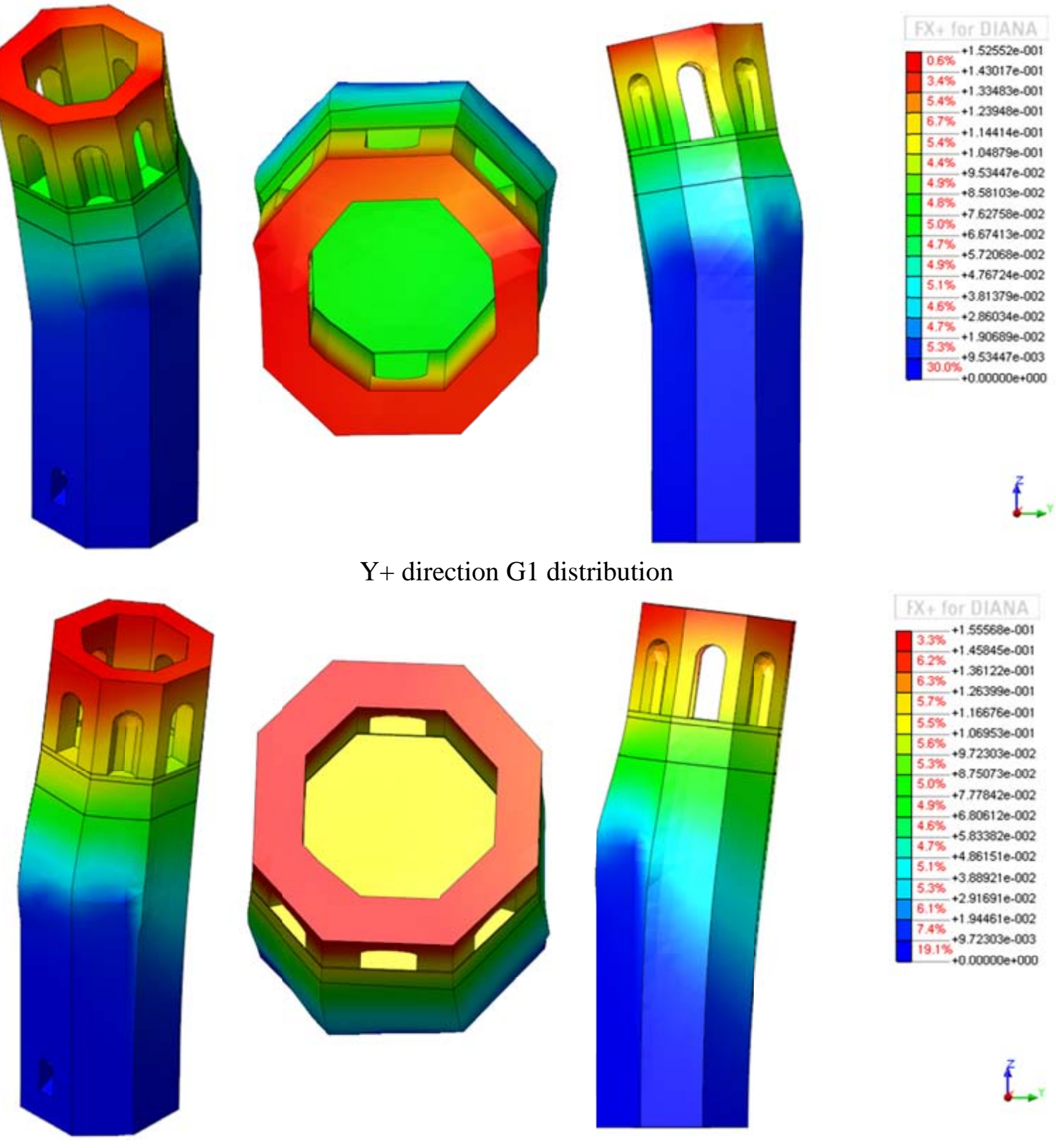

$\mathrm{Y}+$ direction G1 distribution
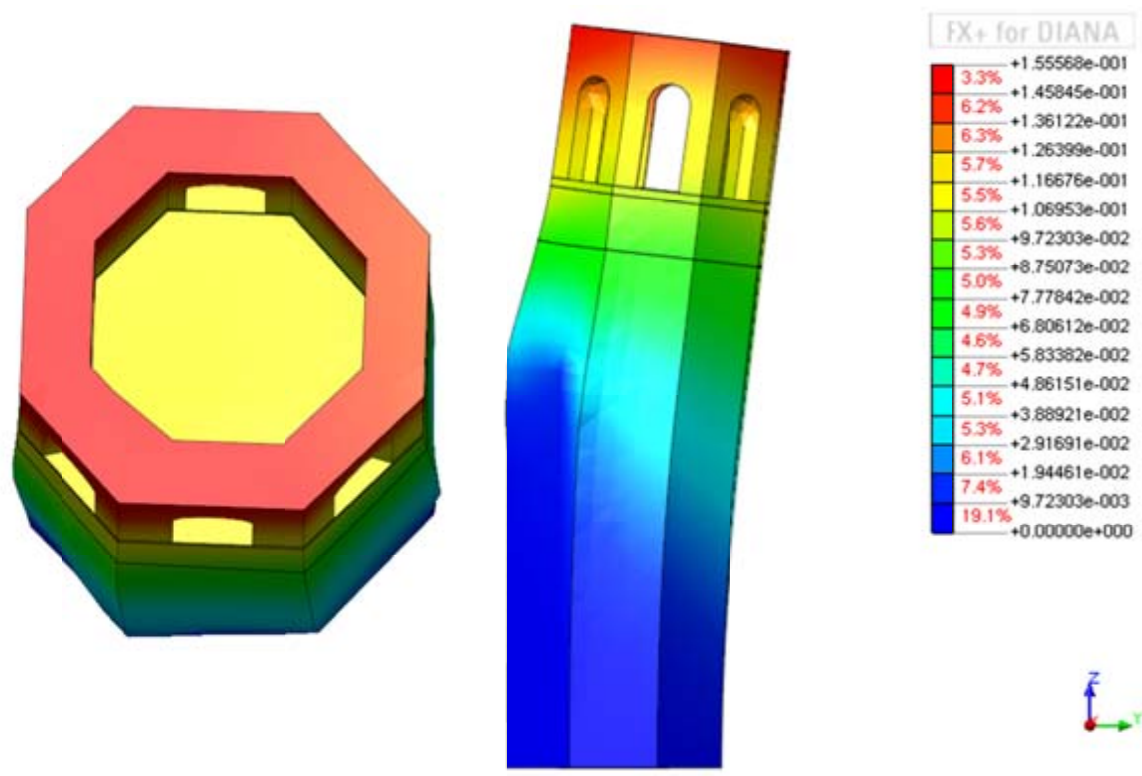

Fig. (12). Deformed shapes at peak provided by the commercial code. Y direction.

Table 6. Mechanical Properties Assumed for the Interfaces for the Interfaces within the Detailed FEM Discretization of the Belfry

\begin{tabular}{|c|c|c|}
\hline$C$ & $\Phi$ & $\psi$ \\
\hline \hline Cohesion [MPa] & Friction angle [ $\left.{ }^{\circ}\right]$ & Dilatancy angle $^{\circ}{ }^{\circ}$ ] \\
\hline 0.01 & 10 & 10 \\
\hline
\end{tabular}

fined in each case, with a clear formation of an inclined failure surface and a rigid body movement of the upper part with respect to the lower around a cylindrical hinge belonging to the cracked surface.

In several cases, a non-negligible concentration of cracks may be appreciated at the base of the belfry and diffusing in the central and lower part. Such a numerical result seems to reflect quite accurately the behavior exhibited by the tower during the L'Aquila earthquake (2009), Fig. (18). Indeed, how it is possible to notice, the belfry results completely collapsed. From a detailed in-situ survey of the damages of the lower part and the ruins of the upper part, it appears clear that the failure mechanism associated to the partial collapse 

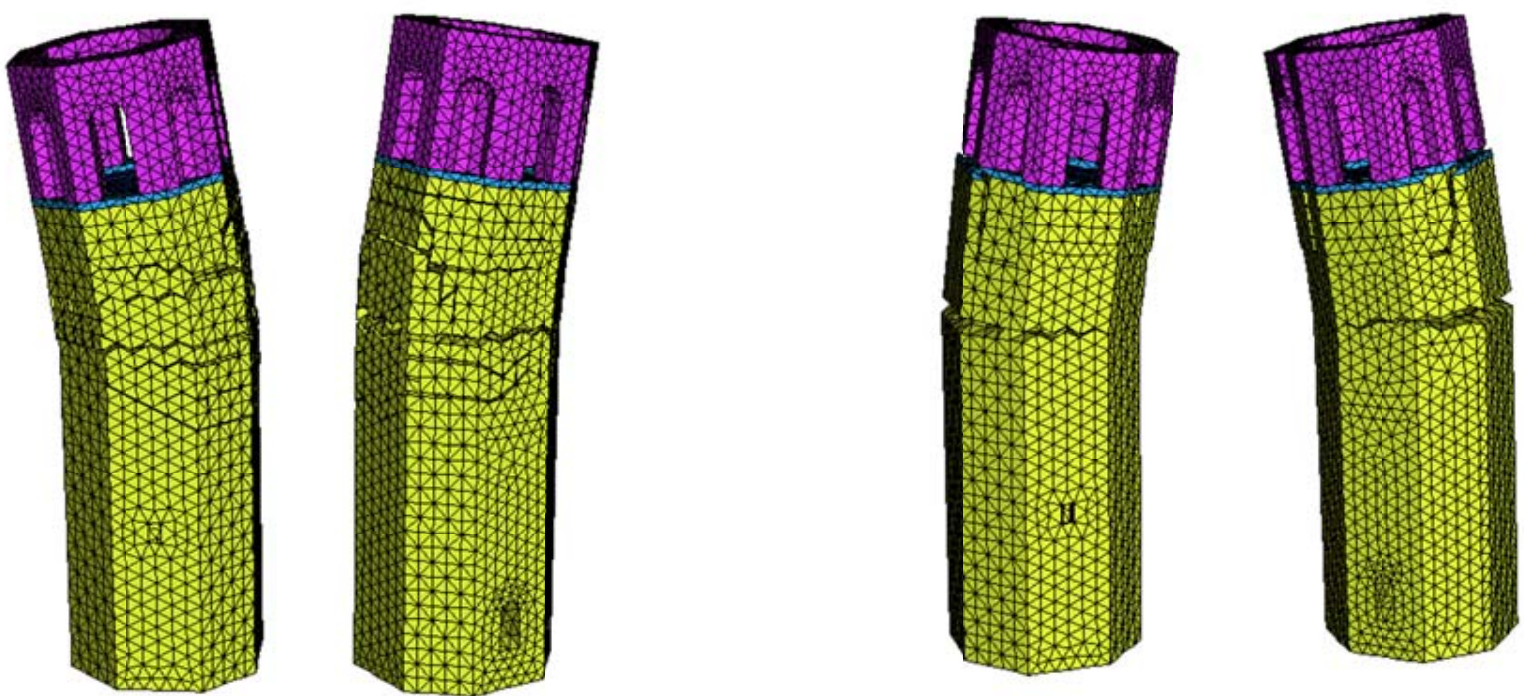

$\mathrm{X}+$

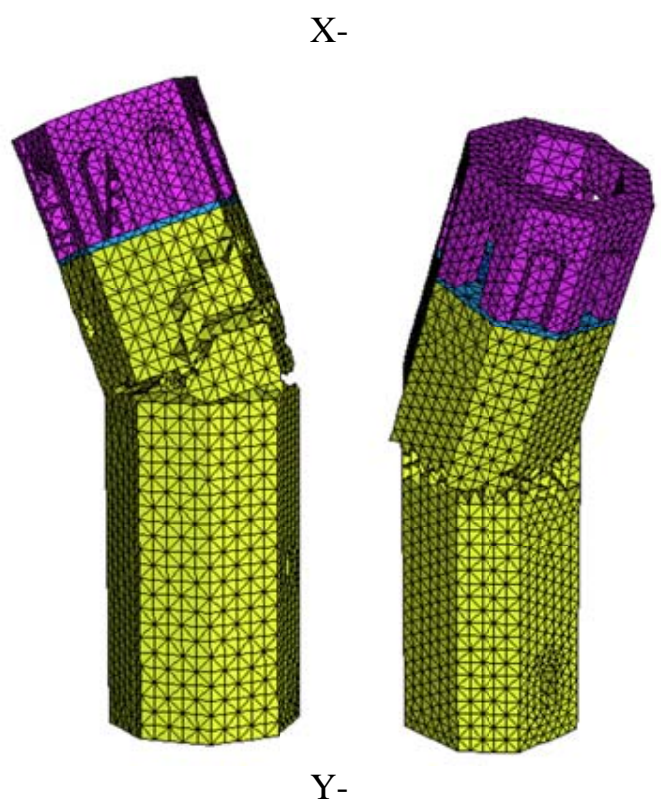

$\mathrm{Y}+$

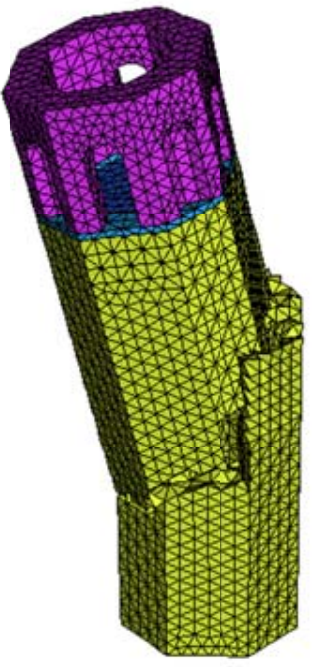

$\mathrm{Y}-$

Fig. (13). Deformed shapes at collapse provided by limit analysis, G1 horizontal forces distributions.

was a full detachment of the belfry from the lower part of the tower in correspondence of the concrete curb.

The un-collapsed lower part of the tower shows also an evident inclined lesion on the east side, which is compatible with the numerical crack pattern on the east side obtained when an earthquake in Y direction Fig. (16) is applied.

\section{COLLAPSE MECHANISM OF THE BELFRY}

From post-earthquake surveys, it has been hypothesized that the collapse of the belfry was due to a failure mechanism associated to sliding and tilting of the upper part, probably caused by the presence of the concrete curb immediately under the belfry. In order to investigate such issue numerically, a further FEM model has been arranged using the same commercial code (DIANA 9.4.3 [22]), and modeling only the belfry of the tower, but introducing interface element between the belfry and the curb and between the frame and the curb. Immediately under the curb, an additional small portion of the tower has been modeled, this latter assumed rigidly constrained at the base Fig. (19) The aim of the simulation is to reproduce both sliding and overturning of the upper part and compare the corresponding collapse acceleration to that required by code of practice specifics. The mechanical properties assumed for interface elements are reported in Table 7.

In order to evaluate the seismic spectral acceleration $\mathrm{a}_{0}$ * that triggers the collapse of the belfry, an incremental nonlinear analysis has been performed on the detail of the belfry.

Within this structural schematization, vertical loads have been applied to the belfry to represent the roof and the bells, superimposed with a horizontal acceleration -constant along the height- that has been incremented until the collapse of 
the belfry. Due to the symmetry of the structural element, the analysis has been performed only in one direction.

The resultant deformed shape at failure is represented in Fig. (20). As can be noted, a sliding of the upper part with rotation of the belfry is present at failure, a collapse mechanism compatible to that observed during the seismic event.

Having a look into the pushover curve (maximum horizontal displacement vs incremented horizontal acceleration), it can be noted that the collapse multiplier for the acceleration Fig. (21) is the following:

$\mathrm{c}=0.28$

therefore, the seismic spectral acceleration results:

$\mathrm{a}_{0}^{*}=\frac{\mathrm{c} . \mathrm{g}}{\mathrm{e}^{*} \mathrm{~F}_{\mathrm{c}}}=\frac{0.28 . \mathrm{g}}{0.95 \times 1.35}=0.22 \mathrm{~g}$ where:

- $\mathrm{g}$ is the gravity acceleration

- $\mathrm{e}^{*}=\frac{\mathrm{gM}^{*}}{\sum_{\mathrm{i}=1}^{\mathrm{n}} \mathrm{P}_{\mathrm{i}}}=0.95:$ fraction of participation mass

- $\mathrm{M}^{*}=\frac{\left(\sum_{\mathrm{i}=1}^{\mathrm{n}} \mathrm{P}_{\mathrm{i}}\right)^{2}}{\mathrm{~g}\left(\sum_{\mathrm{i}=1}^{\mathrm{n}} \mathrm{P}_{\mathrm{i}} \delta_{\mathrm{x}, \mathrm{P}_{\mathrm{i}}}{ }^{2}\right)}=1901.63$ is the participation mass in $\mathrm{Kg}$

- $\quad \mathrm{P}_{\mathrm{i}}$ is a body force and represents the vertical load applied element by element along the height of the structure
X- direction G1 distribution
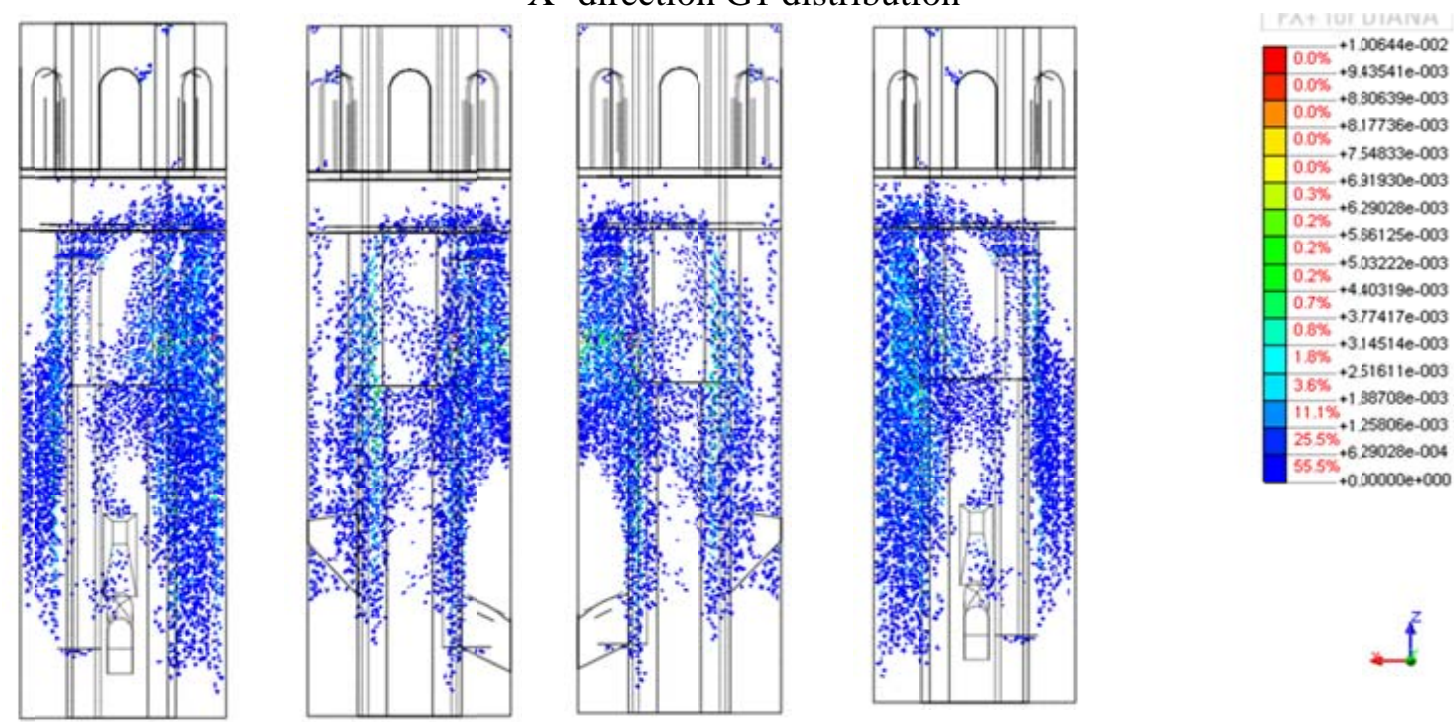

$\mathrm{X}+$ direction $\mathrm{G} 1$ distribution

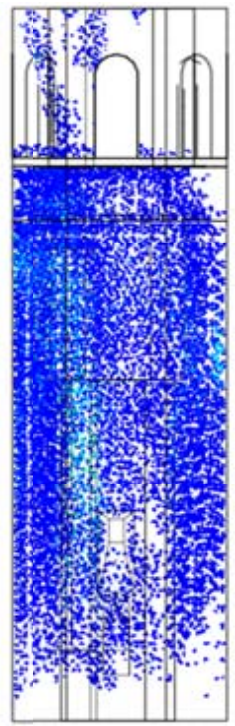

West Side

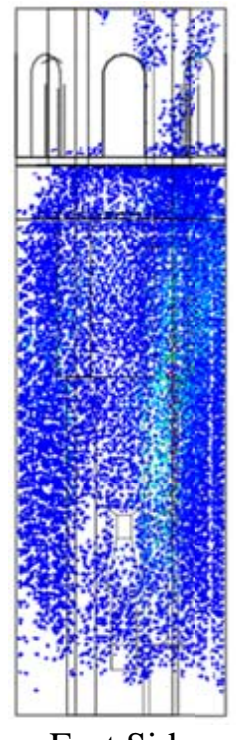

East Side

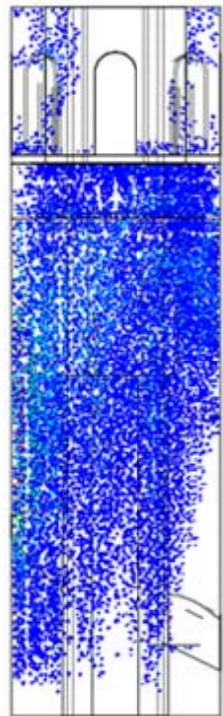

Nord side

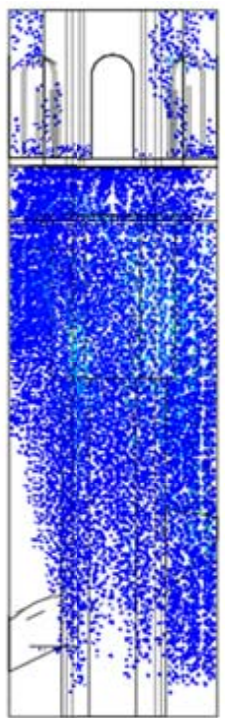

South side

Fig. (14). Numerical crack patterns, $X$ direction, G1 distribution 

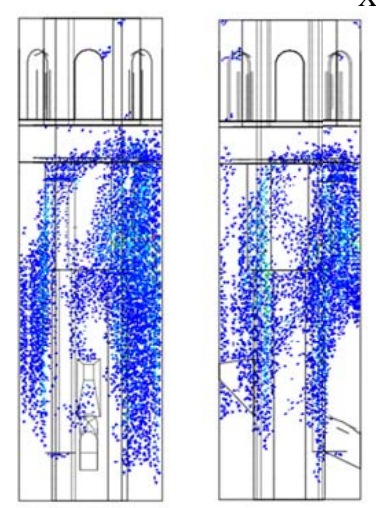

X- direction G2 distribution
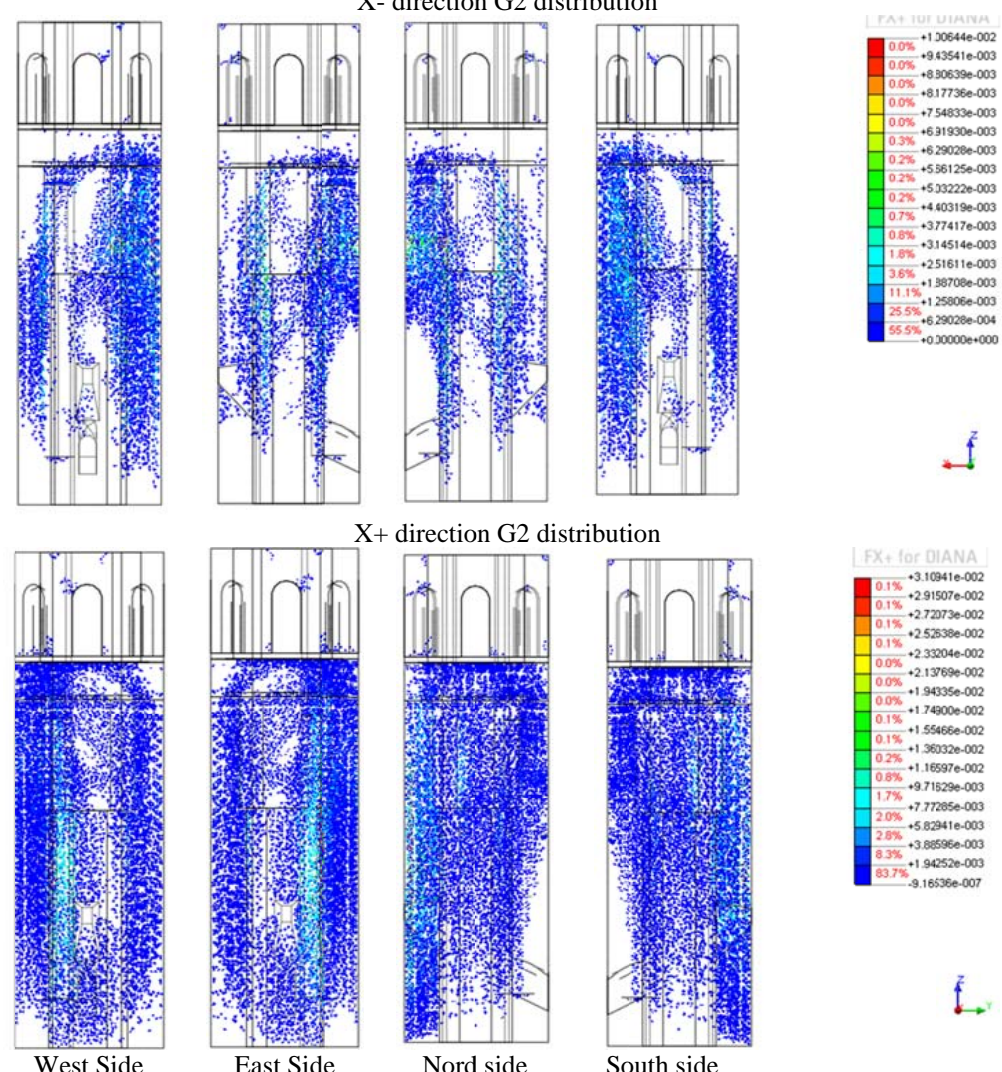

$\mathrm{X}+$ direction $\mathrm{G} 2$ distribution
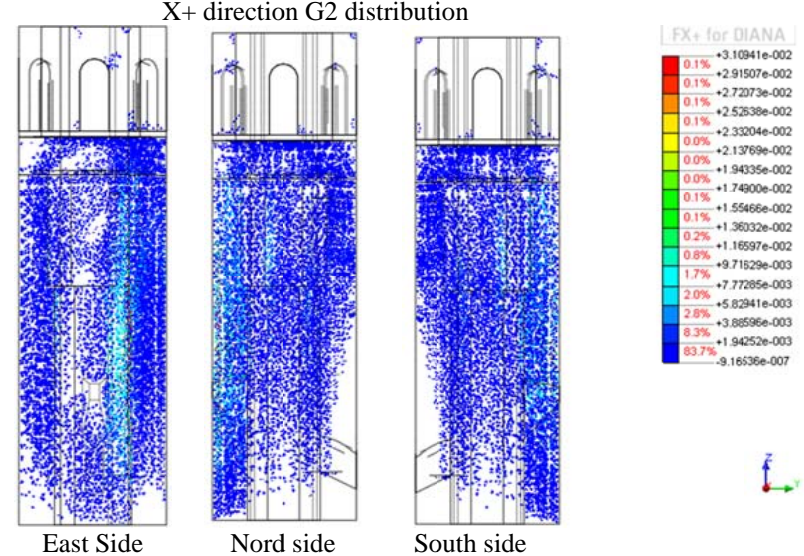

Fig. (15). Numerical crack patterns, $\mathrm{X}$ direction, G2 distribution.
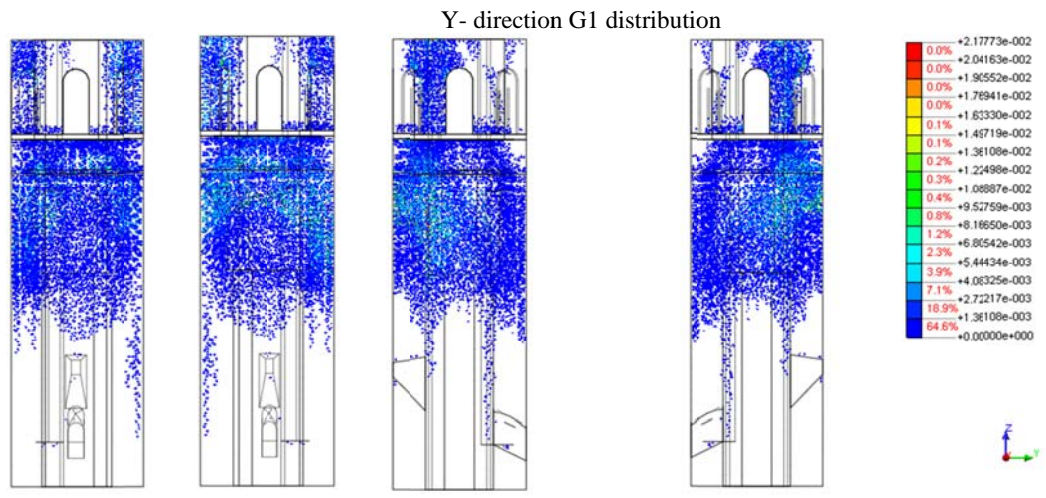

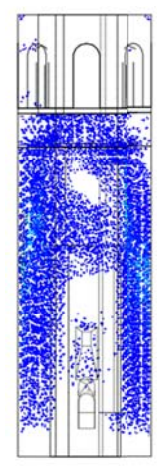

West Side

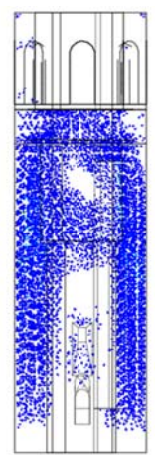

East Side

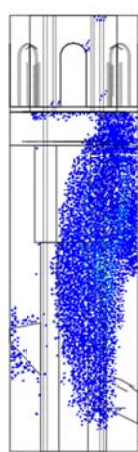

Nord side

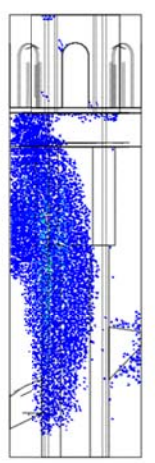

South side

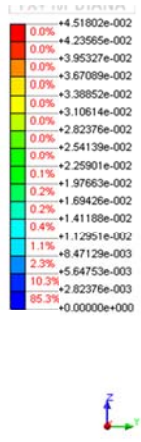

Fig. (16). Numerical crack patterns, Y direction, G1 distribution. 

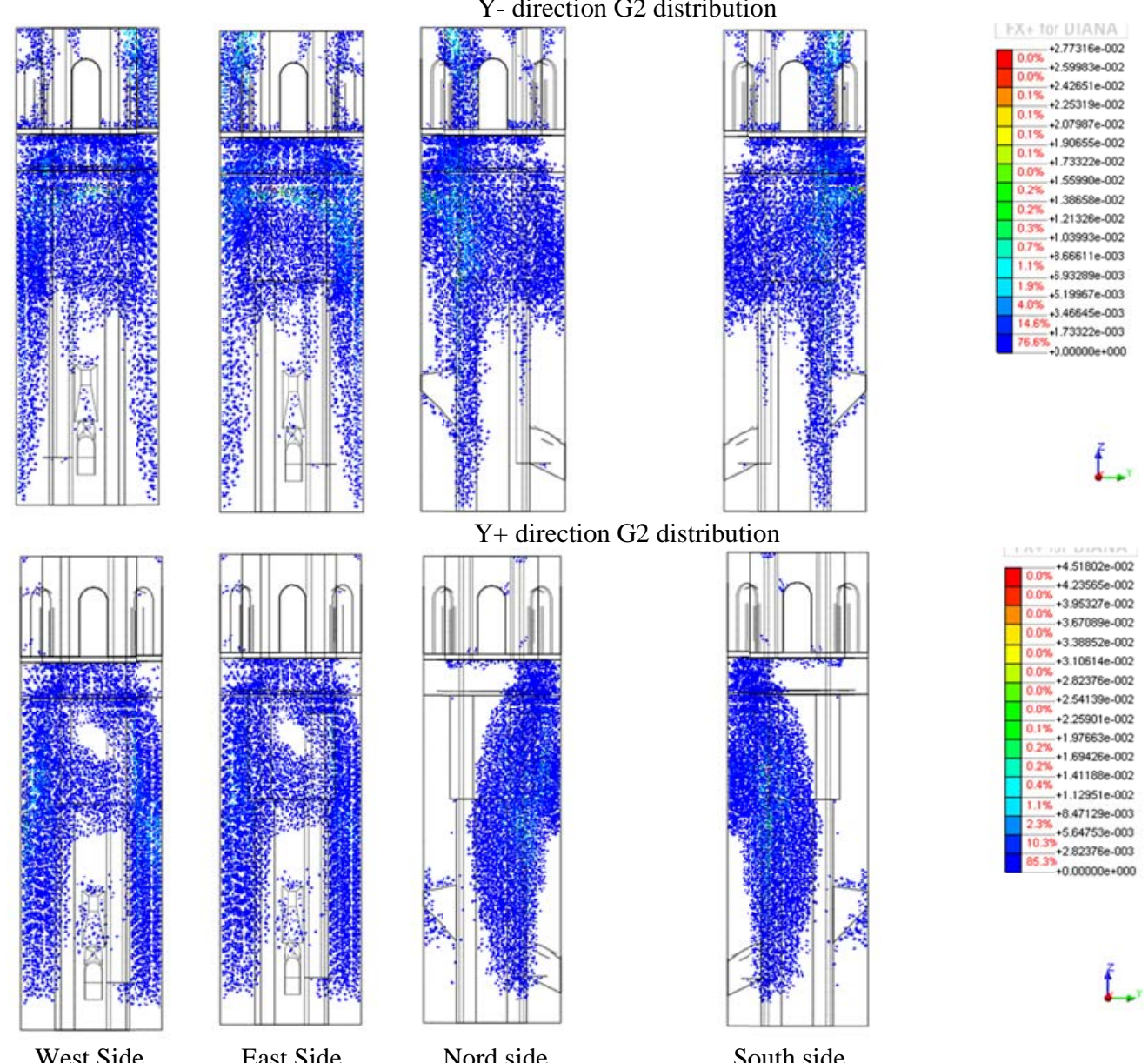

West Side

East Side

Nord side

South side

Fig. (17). Numerical crack patterns, Y direction, G2 distribution.
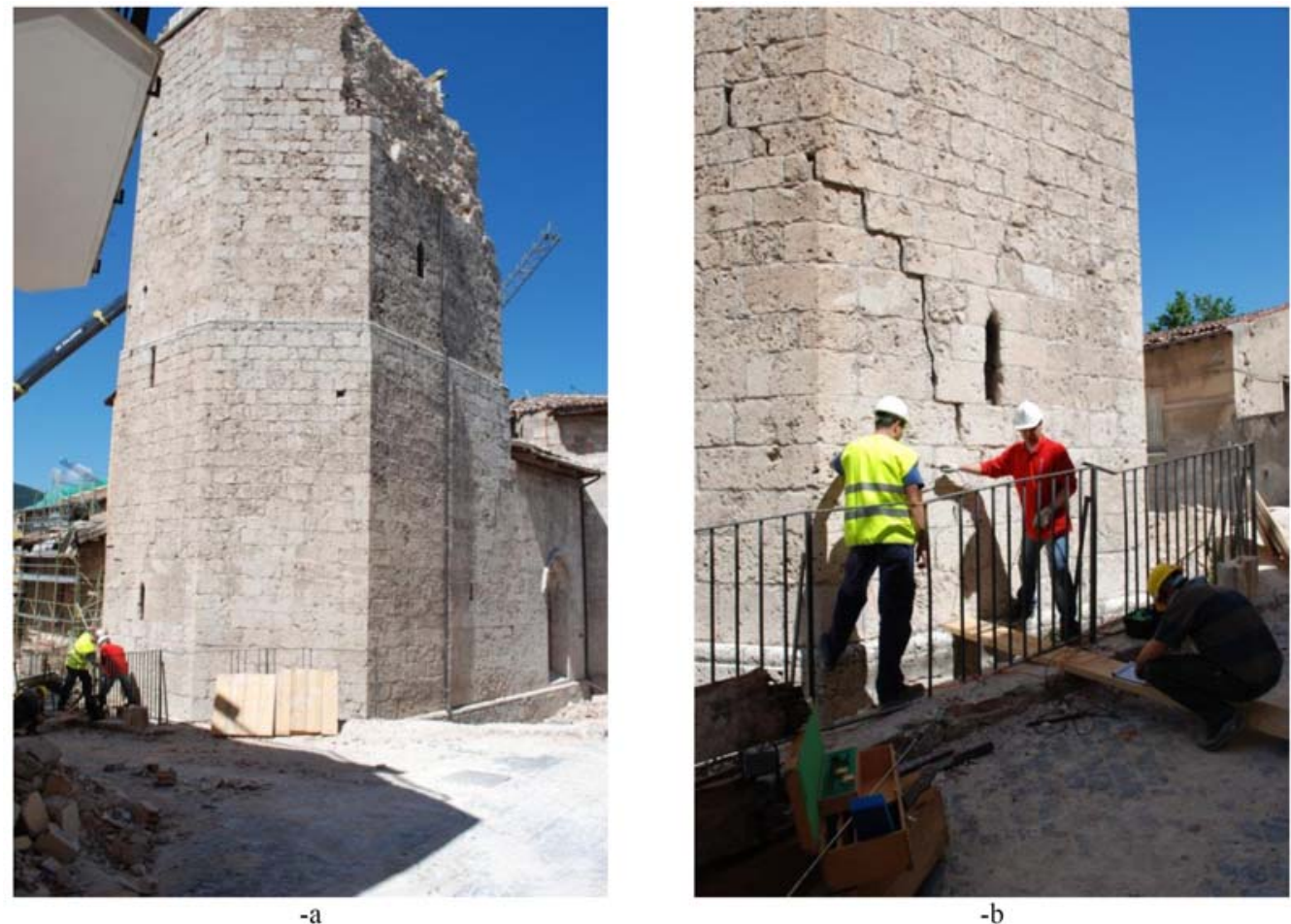

$-b$

Fig. (18). -a: The tower after the L'Aquila earthquake (2009) and (-b) vertical cracks near the base 

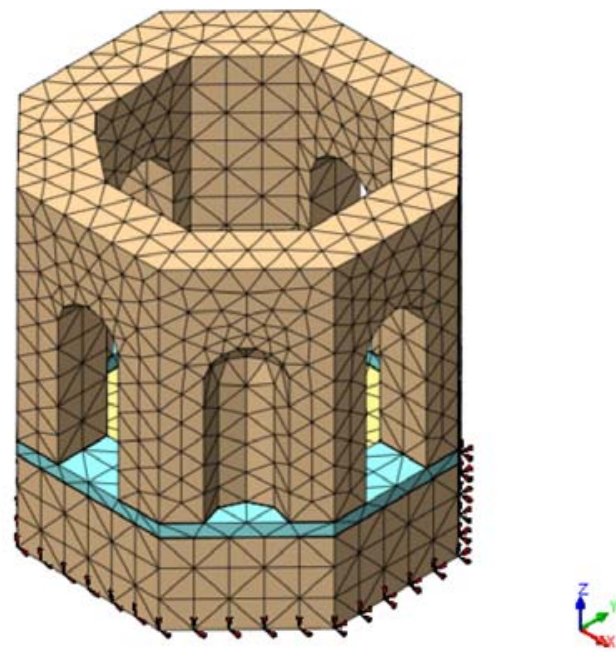

Fig. (19). FEM model of the belfry.
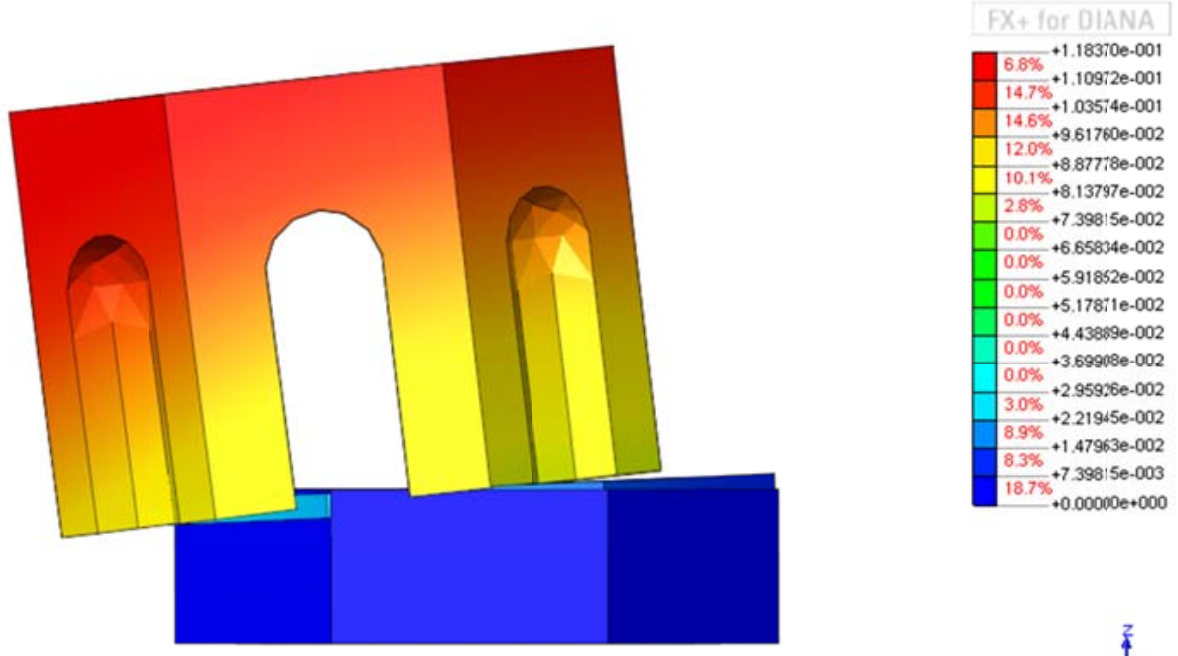

[UNIT] kN , m

[DATA] Structural Nonlinear, TDEXYZM, Load Step $81(0.273002)$

Fig. (20). collapse mechanism of the belfry.

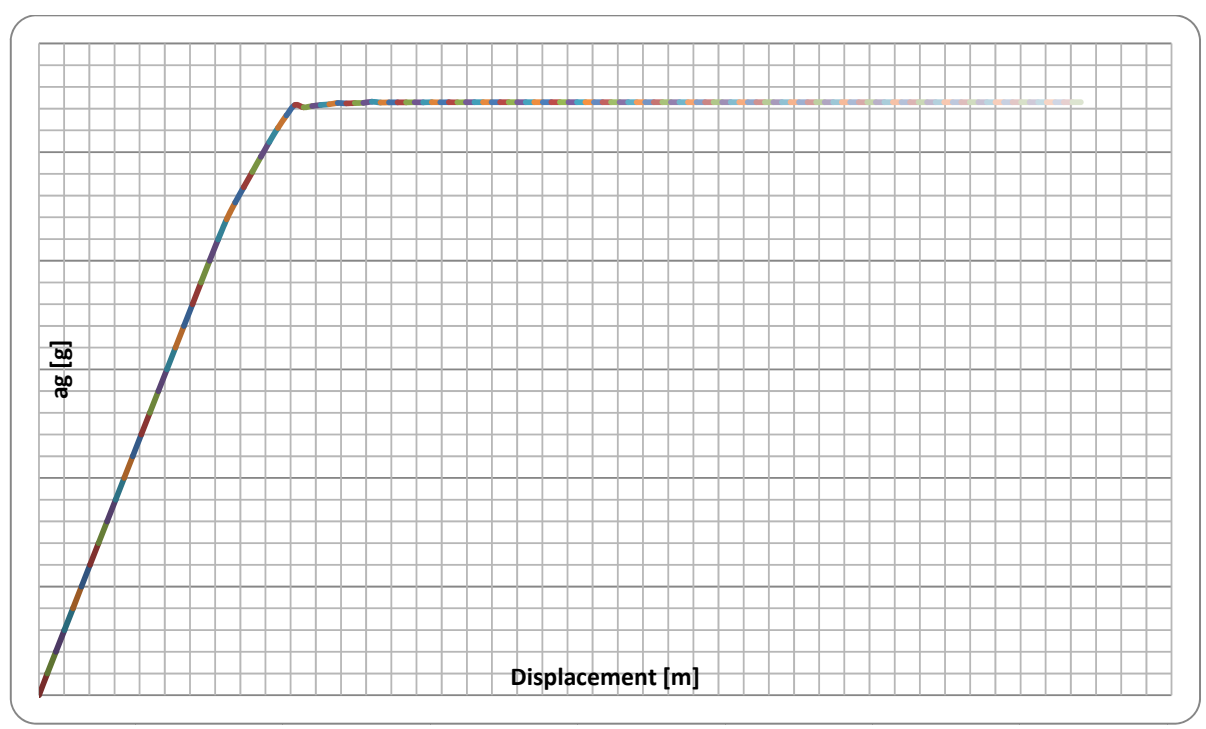

Fig. (21). Belfry mechanism. Curve representing horizontal displacement vs horizontal acceleration. 
- $\delta_{\mathrm{x}, \mathrm{P}_{\mathrm{i}}}$ is a virtual displacement of the point of application of the vertical load.

The seismic spectral acceleration has been compared with spectral acceleration required by the site, as defined by Italian Norms [17], taking into account that the collapse mechanism occurs at a higher quote with respect to the foundation level:

$$
\frac{\mathrm{S}_{\mathrm{e}}\left(\mathrm{T}_{1}\right) \psi(\mathrm{z}) \cdot \gamma}{\mathrm{q}}=\frac{0.6844 \times 0.79 \times 1.2}{2}=0.324 \mathrm{~g}
$$

where:

- $\mathrm{S}_{\mathrm{e}}\left(\mathrm{T}_{1}\right)$ is the elastic spectrum defined by Italian Norms

- $\mathrm{T}_{1}$ is the first vibration mode of the entire structure calculated by modal analysis

- $\psi(\mathrm{z})=\mathrm{Z} / \mathrm{H}$, where $\mathrm{Z}$ is the height of the centroid of the lines belonging to the bond between the blocks involved in the mechanism and the rest of the structure and $\mathrm{H}$ is the height of the structure

- $\quad \gamma$ is the participation factor

Comparing Equation (2) with Equation (3), it can be seen that the collapse mechanism of the belfry is not verified according to the Italian norms.

\section{CONCLUDING REMARKS}

In the present paper, detailed 3D non linear numerical analyses have been performed on the bell tower of the San Pietro di Coppito Church in L'Aquila. The tower suddenly collapsed during the devastating earthquake occurred in April 2009. It is therefore very interesting to perform analyses to provide an ex-post evaluation of the causes at the base of the collapse and give operative design information for the reconstruction, in compliance with new seismic code requirements.

For this aim, two different numerical analyses have been performed, namely non-linear static (pushover) and limit analysis. In both cases, to provide comparable results, the same full 3D detailed FE model of the structure has been adopted, changing the seismic load direction and assuming different distributions of the equivalent static horizontal load. When dealing with the FE incremental analysis, a commercial code has been utilized assuming for masonry a smeared crack isotropic model. For limit analysis, a non-commercial full 3D code developed by the authors was used, providing good estimates of limit loads and failure mechanisms, to compare with standard FE results. From numerical simulations, the role played by the actual geometry and by the masonry mechanical characteristics of the tower has been investigated, as well as a detailed comparison of failure mechanisms provided by the incremental FEM and limit analysis was provided.

\section{CONFLICT OF INTEREST}

The authors confirm that this article content has no conflicts of interest.

\section{ACKNOWLEDGEMENTS}

None declared.

\section{REFERENCES}

[1] Ministero Per I Beni E Le attività Culturali, Italia. "Linee Guida per la valutazione e riduzione del rischio sismico del patrimonio culturale allineate alle nuove Norme Tecniche per le Costruzioni, (in Italian)", 2011.

[2] D. Abruzzese, L. Miccoli and J. Yuan, "Mechanical behavior of leaning masonry Huzhu Pagoda," J. Cult. Herit., vol. 10, p. 480486, 2009.

[3] Carpinteri, S. Invernizzi and G. Lacidogna, "Numerical assessment of three medieval masonry towers subjected to different loading conditions," Mas. Int., vol. 19, pp. 65-75, 2006.

[4] F. Pena, P. B. Lourenco, N. Mendez and D. Oliveira, "Numerical models for seismic assessment of an old masonry tower," Eng. Struct., vol. 32, pp. 1466-1478, 2010.

[5] Bayractar, A. Sahin, M. Ozcan and F. Yildirim, "Numerical damage assessment of Haghia Sophia bell tower by nonlinear FE modeling," Appl. Math. Model., vol. 34, pp. 92-121, 2010.

[6] S. Ivorra e F. J. Pallares, "Dynamic investigations on a mason-ry bell tower," Eng. Struct., vol. 28, pp. 660-667, 2006.

[7] G. Russo, O. Bergamon, L. Damiani e D. Lugato, "Exper-imental analysis of the Saint Andrea masonry tower in Venice. A new method of determination of Tower Global Young's Modulus," Eng. Struct., vol. 32, pp. 353-360, 2010.

[8] J. Heyman, "Leaning Towers," Meccanica, vol. 27, pp. 153-159, 1992.

[9] K. Bernardeschi, C. Padovani and G. Pasquinelli, "Numerical modelling of the structural behavior of Buti's bell tower," J. Cult. Herit., vol. 5, pp. 371-378, 2004.

[10] S. Casolo, "A three-dimensional model for vulnerabilità analysis of slender masonry medieval towers," J. Earthq. Eng., vol. 5, no. 2, pp. 187-204, 1998.

[11] Anzani, L. Binda, A. Carpinteri, S. Invernizzi and G. Lacidogna, "A multilevel approach for the damage assessment of Historic masonry towers," J. Cult. Herit., vol. 11, pp. 459-470, 2010.

[12] G. Milani, S. Casolo, A. Naliato and A. Tralli, "Seismic assessment of mediaeval masonry tower in the northern Italy: full non-linear static and dynamic analyses," Int. J. Archit. Herit., vol. 6(5), pp. 489-524, 2012.

[13] G. Milani, P. B. Lourenco and A. Tralli, "Homogenization approach for the limit analysis of out-of-plane loaded masonry walls," J. Struct. Eng.-ASCE, vol. 132, no. 10, pp. 1650-1663, 2006.

[14] P. B. Lourenco, G. Milani, A. Tralli and A. Zucchini, "Analysis of masonry structures: review of and recent trends in homogenisation techniques," Can. J. Civil. Eng., vol. 34, no. 11, pp. 1443-1457, 2007.

[15] G. Milani, "Homogenized limit analysis of FRP-reinforced masonry walls out-of-plane loaded," Comput. Mech., vol. 43, pp. 617639, 2009.

[16] G. Milani, F. A. Zuccarello, R. Olivito and A. Tralli, "Heterogeneous upper-bound finite element limit analysis of masonry walls outof-plane loaded," Comput. Mech., vol. 40, no. 6, pp. 911-931, 2007.

[17] Consiglio Superiore dei lavori Pubblici, Italia. " Instructions 2009, Circolare esplicativa, $\mathrm{n}^{\circ}$ 617", 2009.

[18] G. Milani, P. Lourenco and A. Tralli, "Homogenised limit analysis of masonry walls. Part I: failure surfaces," Comput. Struct., vol. 83, no. 3-4, pp. 166-180, 2006.

[19] G. Milani, "3D upper bound limit analysis of multi-leaf ma-sonry walls," Int. J. Mech. Sci., vol. 50, no. 4, pp. 817-836, 2008.

[20] G. Milani, E. Milani and A. Tralli, "Upper Bound limit analysis model for FRP-reinforced masonry curved structures. Part I: unreinforced masonry failure surfaces," Comput. Struct., vol. 87, no. 23-24, pp. 1516-1533, 2009.

[21] G. Milani, "Simple lower bound limit analysis homogenization model for in- and out-of-plane loaded masonry walls," Constr. Build. Mater., vol. 25, pp. 4426-4443, 2011.

[22] TNO Building \& Construction Research, "DIANA 9.4.3, 2010. User's guide," Delft, 2010. 
[23] P. B. Lourenco, "Assessment, diagnosis and strengthening of Outeiro Church, Portugal," Constr. Build. Mater., vol. 19, pp. 634-645, 2005 .
[24] Consiglio Superiore Dei Lavori Pubblici, Italia. "NTC 2008, Nuove Norme Tecniche per le Costruzioni", 2008.

Received: March 29, 2012

Revised: May 11, 2012

Accepted: July 8, 2012

(C) Milani et al.; Licensee Bentham Open.

This is an open access article licensed under the terms of the Creative Commons Attribution Non-Commercial License (http://creativecommons.org/licenses/ by-nc/3.0/) which permits unrestricted, non-commercial use, distribution and reproduction in any medium, provided the work is properly cited. 